\title{
Active ginseng components in cognitive impairment: Therapeutic potential and prospects for delivery and clinical study
}

\author{
Md. Jakaria ${ }^{1}$, Md. Ezazul Haque ${ }^{1}$, Joonsoo Kim ${ }^{1}$, Duk-Yeon Cho ${ }^{1}$, In-Su Kim ${ }^{1,2}$ and \\ Dong-Kug Choi ${ }^{1,2}$ \\ ${ }^{1}$ Department of Applied Life Science, Graduate School, Konkuk University, Chungju 27478, Republic of Korea \\ ${ }^{2}$ Department of Integrated Bioscience \& Biotechnology, College of Biomedical and Health Science, and Research Institute of \\ Inflammatory Disease, Konkuk University, Chungju 27478, Republic of Korea
}

Correspondence to: Dong-Kug Choi, email: choidk@kku.ac.kr

Keywords: cognitive impairment; ginseng; active components; potential

Received: May 25, $2018 \quad$ Accepted: August 10, $2018 \quad$ Published: September 11, 2018

Copyright: Jakaria et al. This is an open-access article distributed under the terms of the Creative Commons Attribution License 3.0 (CC BY 3.0), which permits unrestricted use, distribution, and reproduction in any medium, provided the original author and source are credited.

\section{ABSTRACT}

Cognitive impairment is a state that affects thinking, communication, understanding, and memory, and is very common in various neurological disorders. Among many factors, age-related cognitive decline is an important area in mental health research. Research to find therapeutic medications or supplements to treat cognitive deficits and maintain cognitive health has been ongoing. Ginseng and its active components may have played a role in treating chronic disorders. Numerous preclinical studies have confirmed that ginseng and its active components such as ginsenosides, gintonin, and compound $K$ are pharmacologically efficacious in different models of and are linked to cognitive impairment. Among their several roles, they act as an anti-neuroinflammatory and help fight against oxidative stress and modulate the cholinergic signal. These roles may be involved in enhancing cognition and attenuating impairment. There have been some clinical studies on the activity of ginseng in cognitive impairment, but many ginseng species and active compounds remain to be investigated. In addition, new formulations of active ginseng components such as nanoparticles and liposomes could be used for preclinical and clinical models of cognitive impairment. Here, we discuss the therapeutic potential of active ginseng components in cognitive impairment and their chemistry and pharmacokinetics and consider prospects for their delivery and clinical study with respect to cognitive impairment.

\section{INTRODUCTION}

Ginseng is a perennial plant belonging to the genus Panax and family Aralliaceae [1]. The word Panax means "all-healing" in Greek based on a view that ginseng is influential in healing all kinds of disease [2]. Among the different species of ginseng, the most commonly investigated species are Panax ginseng (frequently called as just ginseng or Korean ginseng), P. quinquefolius (also known as American ginseng) and P. notoginseng (also known as Chinese ginseng or Sanchi) [3]. Ginseng roots, stems and leaves have been used in traditional herbal medicine for over 2000 years [4]. Ginseng and its active components have exhibited a wide range of characteristics, including antioxidant, antiaging, antifatigue, adaptogenic, restorative, vasodilatory, anti-inflammatory, immunomodulatory, anticancer and antidiabetic [2, 4]. In addition, in models of neurological disorders, the active components of ginseng showed anti-depressive, antistress, antiepileptic and antipsychotic activities [5-8].

Cognitive health is a major factor in the life of the elderly and in preserving the ability to function. Vital elements of cognitive health include mental abilities and acquired skills, along with the aptitude to apply them so 
as to participate in a specific activity [9]. Age-related decline of cognitive functions is a leading challenge in mental health research. Because no curative treatment for dementia currently exists, an alternative would be to find way to attenuate cognitive impairment in older people, which, in turn, could delay the onset of dementia [10]. Moreover, in many neurological disorders, the cognitive functions of patient might be affected. For example, Alzheimer's disease (AD) is the most common cause of dementia and is characterized by memory loss and cognitive impairment $[11,12]$. Cognitive functions can be impaired in other neurological disorders such as Parkinson's disease, multiple sclerosis and stroke [13-15].

Shi-Zhen Li recorded anxiolytic, antidepressant and cognition-enhancing effects of ginseng in the most comprehensive pre-modern herbal text (Ben Cao Gang $\mathrm{Mu}$ ), which was compiled during the Ming Dynasty in China [15]. Recent research shown that ginseng and its active components possible have effects against neurodegenerative diseases and stroke [16-19]. Additionally, in a mechanistic study using rat model [20], saponins from Panax japonicus (also known as Japanese ginseng) attenuated age-related neuroinflammation by regulating signaling pathways of mitogen-activated protein kinase (MAPK) and nuclear factor kappalight-chain-enhancer of activated B cells (NF- $\mathrm{B}$ ). The compound Schisandra-Ginseng-NotoginsengLycium produced learning and memory enhancement in scopolamine-induced learning and memory loss in mice [21]. Moreover, the recently discovered protopanaxadiol derivative 1-(3,4-dimethoxyphenethyl)-3(3-dehydroxyl-20(S)-protopanaxadiol-3b-yl)-urea showed pharmacological activity in an AD model. This compound improved the daily activities and decreased cognitive deficits in APP/PS1 transgenic mice. It also reduced amyloid beta $(A \beta)$ production mainly by inhibiting the protein kinase R (PKR)-like endoplasmic reticulum kinase (PERK) and eukaryotic initiation factor 2 (eIF2) signal-mediated beta-site APP-cleaving enzyme 1 translation. The protopanaxadiol derivative also stimulated $A \beta$ clearance by promoting autophagy as a phosphatidylinositol-3 kinase (PI3K) inhibitor via $\mathrm{PI} 3 \mathrm{~K} /$ protein kinase $\mathrm{B}(\mathrm{Akt}) /$ mammalian target of rapamycin (mTOR) signaling pathway, while exhibiting a neuroprotective effect involving attenuation of endoplasmic reticulum (ER) stress [22]. In our recent article, we show that the active constituents of ginseng produce their effects in neurodegenerative diseases by modulating various ion channels and molecular signaling pathways [23]. Considering the importance of and recent evidence about ginseng, herein, we discuss the potential effects of active ginseng components on cognitive impairment and their fundamental chemistry and pharmacokinetics. In addition, we discuss prospects for their delivery and their use in clinical studies of cognitive impairment.

\section{BASIC CHEMISTRY AND CLASSIFICATION OF ACTIVE GINSENG COMPONENTS}

Ginseng root contains several constituents, including triterpene saponins, polysaccharides, peptidoglycans, nitrogen-containing compounds, fatty acids, carbohydrates, phenolic compounds, and essential oil-containing polyacetylenes and sesquiterpenes [24].

The major active components in ginseng are ginsenosides, which are an arrangement of triterpene glycosides (saponins). Ginseng also contains gintonin, a nonsaponin compound [25]. Aamong the 150 ginsenosides isolated from ginseng, 40 are present in $P$. ginseng [26]. Ginsenosides contain a four-ring steroid backbone structure $[27,28]$, and are classified into three groups according to their aglycone structures, namely, oleanane, protopanaxadiol (PPD), and protopanaxatriol (PPT). Ginsenoside Ro is the only member of the oleanane group and contains the oleanolic acid aglycone [29]. Two major groups of ginsenosides are PPD, which includes Rb1, Rb2, Rc, Rd, Rg3, Rh2, and Rh3 and PPT, which includes Re, Rf, Rg1, Rg2, and Rh1 [30].

Both PPD and PPT of ginsenosides exist in glycosylated compounds that contain a non-sugar component with one to four glycoside molecules [29]. Wild ginseng comprises more than $80 \%$ glycosylated major ginsenosides, including Rb1, Rb2, Rc, Rd, Rg1 and Re [31]. Furthermore, pseudoginsenoside-F11 (PF11), an ocotillol-type ginsenoside (saponin), is found in $P$. quinquefolius $[32,33]$. PF11 is also known as a novel partial peroxisome proliferator-activated receptor $\gamma$ (PPAR $\gamma$ ) agonist, which could be developed into a new PPAR $\gamma$-targeted therapeutic drug against type 2 diabetes [33]. Notoginsenoside R1 (NTR1), a novel phytoestrogen isolated from $P$. notoginseng, belongs to the PPT group and a major component in $P$. notoginseng [34-37]. Compound K [20-O- $\beta$-D-glucopyranosyl-20(S)-protopanaxadiol] first isolated from soil bacteria and is a YSB-6-mediated hydrolysate of a mixture of $\mathrm{Rb} 1, \mathrm{Rb} 2$, and $\mathrm{Rc}$ [38]. It is a metabolic product of $\mathrm{Rb} 1$ and $\mathrm{Rb} 2$ metabolized by intestinal bacteria $[38,39]$ through specific metabolic pathways [40]. The chemical structures of various active compounds of ginseng that have been studied with respect to cognitive impairment are shown in Figure 1.

\section{PHARMACOKINETICS OF ACTIVE GINSENG COMPONENTS}

The pharmacokinetics of different active ginseng compounds has been studied in both animals and humans. After oral administration, the level of test compounds are high in the plasma sample, but the rate of absorption of ginsenosides is low [41]. Ginsenosides are not easily absorbed because of their hydrophilicity [42]. The energy- 
dependent absorption profile of ginsenosides in the mucosa of intestine [43-45], and the availability of both intact ginsenosides and their metabolites from the intestines are very low $[39,46,47]$. Gintonin can be absorbed into the intestine via transcellular and paracellular diffusion and the active transport process [48]. In general, the time for ginsenosides to reach maximum concentration (Tmax) in plasma is less than $2 \mathrm{hr}$, signifying that saponins are quickly absorbed and readily distributed in tissues [49, 50]. According to quantitative and statistical analyses, the plasma level of ginsenosides indicates that PPD ginsenosides have a higher concentration and longer half-life than do PPT ginsenosides [51]. After oral administration of Rb1 (only compound $\mathrm{K}$ ) was found in plasma and urine [52]. After dosing at different time intervals, ginsenosides enter into the brain rapidly, but the concentrations rapidly decline with time. The ginsenosides with higher concentrations in the brain are $\mathrm{Rg} 1, \mathrm{Re}, \mathrm{Rb} 1$ and Rc that was shown by a pharmacokinetic study [51]. $\mathrm{Rg} 1$ and $\mathrm{Re}$ are better distributed in the brain and are considered the main components that directly affect

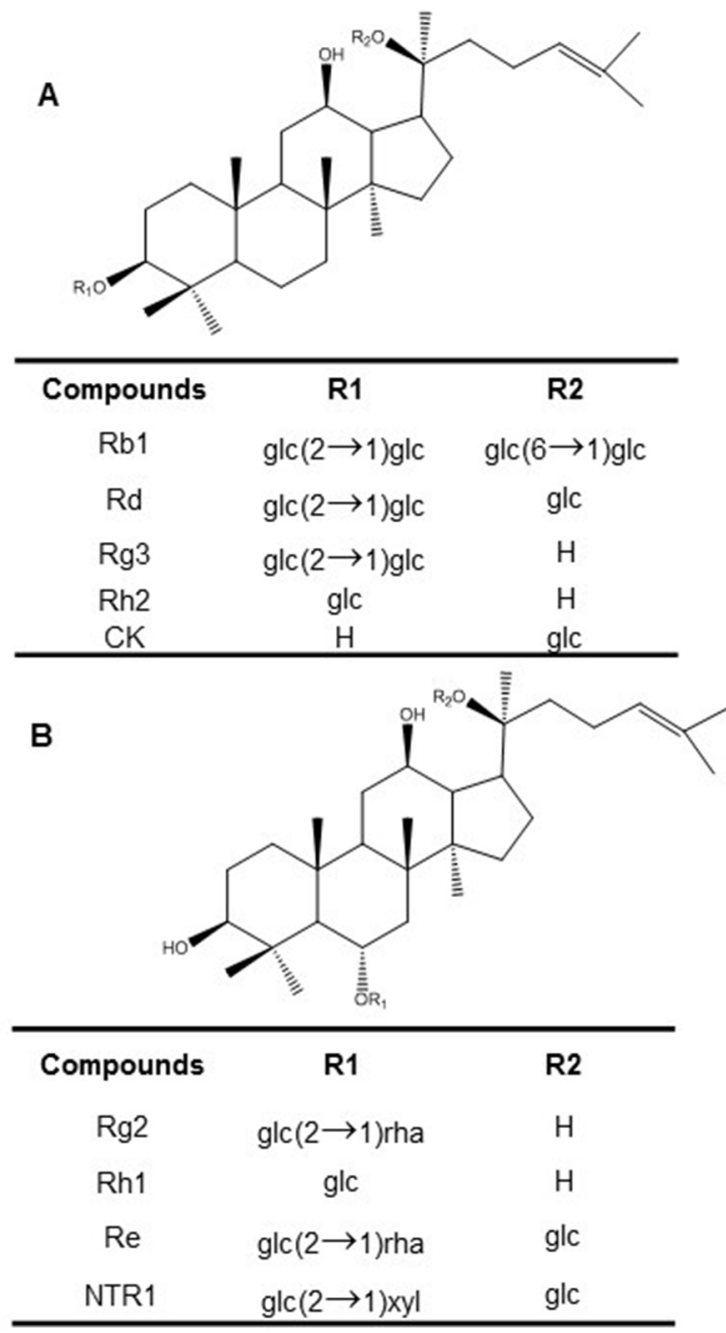

central nervous system (CNS) neurons. Conversely, they are in the circulation a long time, PPD ginsenosides may protect the brain mostly via a peripheral effect. The disposition in the liver and bile tissue confirms that cleared ginsenosides are cleared from circulation [53-55].

After the biotransformation of ginsenosides, microbiota in the gut forms deglycosylated products [55]. The absorbable metabolite compound $\mathrm{K}$ forms after biotransformation by microorganisms or specific enzymes. Several studies indicated that intestinal bacteria isolated from human feces or fungi derived from soil around ginseng roots as well as some food-derived microorganisms hydrolyze ginsenosides to produce compound $\mathrm{K}[56,57]$. The deglycosylated products are better able to permeate and be absorbed than ginsenosides [58]. However, the extensive of the deglycosylated products through active transport shorten the biological half-life, resulting in low systemic exposure [55]. In addition, studies that used co-administration with adrenalin [59] or lipid-based formulations [59, 60] and of the suppression of pglycoprotein efflux system [43] confirmed

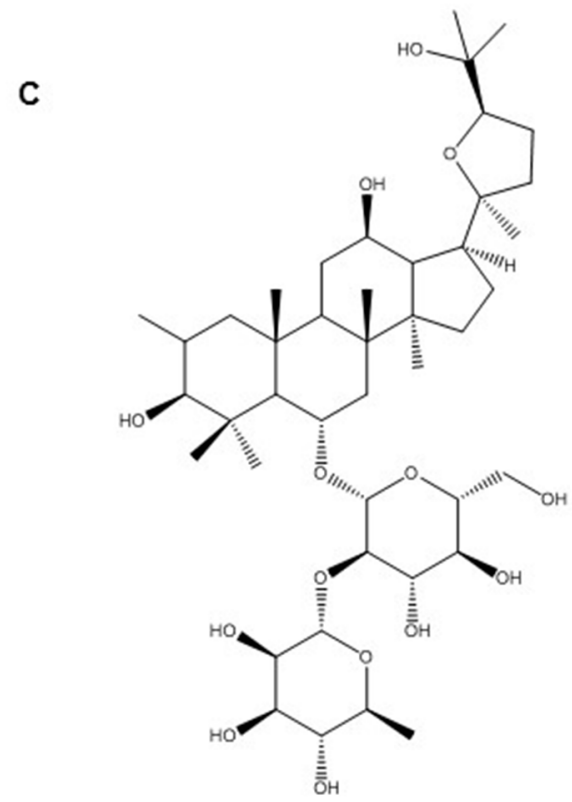

glc: glucopyranose

rha: rhamnopyranose

xyl: xylopyranose

Figure 1: Chemical structures of various active ginseng components: (A) protopanaxadiol type ginsenosides (B) protopanaxatrioltype ginsenosides $(\mathbf{C})$ pseudoginsenoside-F11. 
the increase in oral bioavailability of ginsenosides. Ginsenoside was metabolized by the hepatic cytochrome P450 3A4 (CYP3A4), which is catalyzed the metabolism by oxygenation of the hepatic disposition of ginsenosides [43]. In addition, attachment of additional sugar moieties to the PPD ginsenosides Ra3, Rb1, Rc and Rd blocks their access to biliary transporters and reduces biliary excretion [55], and furthermore, the active transport carried out by ginsenosides and their deglycosylated products for excretion by the biliary system [55]. Time curves of ginsenosides exhibited distinct multiple peaks after oral administration that demonstrating the involvement of enterohepatic recirculation [53]. Approximately, 0.2$1.2 \%$ of ginsenosides were excreted in human urine [61], with the elimination half-lives $\left(T_{1 / 2}\right)$ of $\mathrm{Rg} 1$, Re and $\mathrm{Rb} 2$ between 0.8 and $7.4 \mathrm{~h}$ in rabbits [62]. In humans, the T1/2 of the tested ginsenosides was generally less than $24 \mathrm{~h}$ $[63,64]$.

\section{PHARMACOLOGICAL POTENTIAL OF ACTIVE GINSENG CONSTITUENTS IN MODEL STUDIES OF COGNITIVE IMPAIRMENT}

\section{Ginsenoside Rb1}

In recent studies, $\mathrm{Rb} 1$ produced cognitive enhancing activity in both cisplatin- and isoflurane and surgeryinduced-cognitive impairment rodent models [65, 66]. In the cisplatin-induced impairment model, administration of Rb1 (2 mg/kg for 5 consecutive weeks) effectively ameliorated cisplatin-induced memory impairment in behavioral studies. Rb1 also attenuated cisplatin-induced neuronal loss in the CA1, CA3, and dentate gyrus of the hippocampus, rescued the cholinergic neuron function, and inhibited the oxidative stress and neuroinflammation in the brains of cisplatin-induced rats [65]. In the isoflurane and surgery-induced cognitive impairment model, Rb1 [60 mg/kg, intraperitoneal (i.p.) from 7 days before surgery] attenuated cognitive impairment model and synaptic dysfunction. It also mitigated the elevated levels of isoflurane and surgery-induced reactive oxygen species (ROS), tumor necrosis factor- $\alpha$ (TNF- $\alpha$ ) and interleukin (IL)-6 in the hippocampus of mice [66]. In subarachnoid hemorrhage-induced brain injury in rats, Rb1 (20 mg/kg) reduced brain edema, enhanced neurobehavioral function, and blocked vasculature thickening and spasms [67]. In another recent study, Rb1 treatment ameliorated alteration of leptin-pJAK2-pSTAT3 signaling and leptin-induced brain derived neurotrophic factor (BDNF) expression in the prefrontal cortex of obese mice and improved hyperleptinemia. It also promoted the effect of leptin on neurite branching and elongation and synaptogenesis in prefrontal cortical neurons [68]. Increasing cell survival in the hippocampus may be one way in which Rb1 helps spatial learning and memory, as described in a molecular study [69]. In a comparative study between $\mathrm{Rg} 1$ and Rb1, the latter facilitated learning and memory in a scopolamine-induced mice model. It increased acetylcholine (ACh) levels in the hippocampus and prevented the decrease in the level of scopolamineinduced 5-hydroxytryptamine (5-HT). However, Rb1 has less of an effects than $\mathrm{Rg} 1$ [70]. In another comparative study and a specific study on Rb1, Rb1 attenuated tertbutylhydroperoxide toxicity in the neural progenitor cells, where the nuclear factor (erythroid-derived 2)like $2(\mathrm{Nrf} 2)$ /heme oxygenase-1 pathway was found to be crucial in the intracellular defense against oxidative stress $[71,72]$. In addition, a recent study demonstrated the neuroprotective activity of Rb1 in 1-methyl-4-phenyl1,2,3,6-tetrahydropyridine (MPTP)-induced Parkinson's disease model. Rb1 treatment ameliorated MPTP-induced motor impairment, protected dopaminergic neuron death, and suppressed $\alpha$-synuclein expression and astrogliosis in mouse. It increased glutamate transporter expression through nuclear translocation of $\mathrm{NF}-\kappa \mathrm{B}$, regulated glutamate receptor expression, and promoted synaptic protein expression [73]. Two major pharmacological effects of ginsenoside Rb1 on cognitive impairment are shown in Figure 2.

\section{Ginsenoside Rd}

Ginsenosides $\mathrm{Rd}$ has the potential for treating cognitive impairment in several model studies. In an amyloid $\beta$-protein precursor (APP) transgenic (Tg) mice model, Rd improved learning and memory probably via inhibiting the transcription activity of NF- $\kappa$ B. Suppression of the transcription activity of the NF- $\kappa \mathrm{B}$ pathway might have led to the reduction of proinflammatory cytokines, and the generation of protective factors eventually increased [74]. In addition, $\mathrm{Rd}$ enhanced the learning and memory functions of ovariectomized rats by activating estrogen-like activity through the estrogen receptor. In HT22 cells, Rd upregulated an increase in the level of secreted amyloid precursor protein- $\alpha(\operatorname{sAPP} \alpha)$ to 10 $\mu \mathrm{M}$, which can be inhibited by inhibitors MAPK and PI3K pathways. Estrogen receptor inhibitors prevent $\mathrm{Rd}$ triggered release of $\mathrm{SAPP} \alpha$ and activation of MAPK and PI3K pathways. However, Rd increases expression of $\alpha$-secretase and $\operatorname{sAPP} \alpha$, decreases expression of the $\beta$-secretase and $A \beta$, and promotes phosphorylation of estrogen receptor alpha at the Ser118 residue [75]. In a trimethyltin (TMT)-induced neurotoxicity model, pretreatment with $20 \mu \mathrm{g} / \mathrm{ml} \mathrm{Rd}$ for $24 \mathrm{~h}$ reversed the toxic action. Notably, Rd attenuated the tremor seizures and cognitive decline in behavioral tests and significantly reduced neuronal loss $(P=0.018)$ and active astroglials $(P=0.003)$ compared with the negative control group. The mechanism involved in prevention of TMT-induced cell apoptosis by $\mathrm{Rd}$ treatment is the regulation of B-cell lymphoma 2 (Bcl-2), Bcl-2-like 
protein 4 (Bax) and caspase-3 [76]. Moreover, Rd may promote neurite outgrowth in $\mathrm{PC} 12$ cells by upregulating growth-associated protein-43 expression through both extracellular signal-regulated kinase (ERK)- and adhesion related kinase-dependent signaling pathways [77].

\section{Ginsenoside Re}

Different studies have postulated about the ginsenoside Re activity in cognitive impairment models. $\operatorname{Re}(2 \mu \mathrm{g} / \mathrm{ml})$ produced protective activity via the phospho-p38, iNOS, and COX-2 signaling pathways in lipopolysaccharide (LPS)-induced BV-2 microglial cells [78]. It improves the learning and memory in rats, via a mechanism that may correlate with its enhancing basic synaptic transmission and increasing the magnitude of the long-term potentiation (LTP) of the dentate gyrus in a rat model [79]. In addition, ginsenoside Re (10, 20 , or $50 \mathrm{mg} / \mathrm{kg}$ i.p.) administered during the repeated immobilization stress period significantly inhibited the stress-induced impairment in behavioral tests. It also significantly inhibited the increase tyrosine hydroxylase (TH) expression in the locus coeruleus and the decrease BDNF mRNA expression in the hippocampus [80]. Moreover, Re shows an effect on cognitive function, oxidative stress, and inflammation in streptozotocin- induced diabetic rats. Treatments with $\mathrm{Re}(40 \mathrm{mg} / \mathrm{kg})$ for 8 weeks remarkably attenuated diabetes-associated cognitive decline, which confirmed the involvement of oxidative stress and inflammation in the development of cognitive impairment caused by diabetes [81]. In addition, Re ameliorated high-fat-diet-induced insulin resistance in $\mathrm{C} 57 \mathrm{BL} / 6$ mice. It improved cognitive dysfunction in diabetic mice, as shown by behavioral studies and regulated $\mathrm{ACh}$, acetylcholinesterase (AChE), malondialdehyde, superoxide dismutase (SOD), and oxidized glutathione (GSH)/total GSH by regulating the c-Jun N-terminal protein kinase (JNK) pathway. Therefore, Re could be used to improve high-fat diet-induced insulin resistance by ameliorating hyperglycemia via protecting the cholinergic and antioxidant systems in the mouse brain [82]. In the myocardial ischemia-reperfusion injury rat model, Re has a protective effect, the mechanism of which may be related to the alleviation of damage caused by oxygen free radicals [83]. In a pharmacokinetics study, $\mathrm{Re}$ dose-dependently increased the extracellular levels of dopamine and $\mathrm{ACh}$ in the hippocampus and medial prefrontal cortex, although it had a greater effect in the hippocampus [84]. In addition to the aforementioned models, $\mathrm{Re}$ also protects against phencyclidine (PCP)-induced behavioral changes and mitochondrial dysfunction. Treatment with Re significantly attenuates

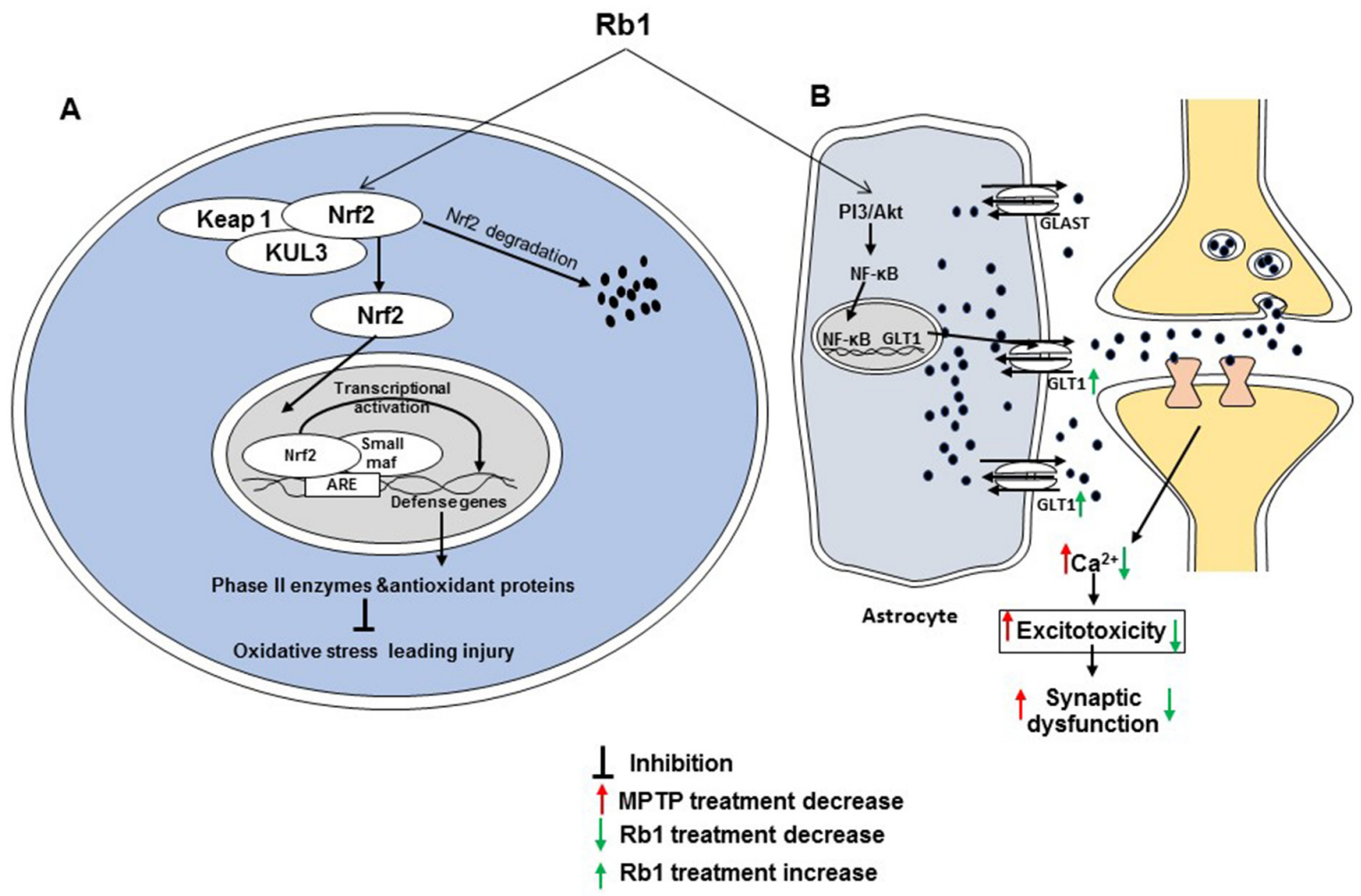

Figure 2: Two major activities of Rb1 associated with cognitive impairment. (A) Rb1 prevents oxidative stress leading to damage by activating the Nrf2 pathway. (B) Rb1 decreases excitotoxicity-mediated synaptic dysfunction by upregulating GLT 1 via the $\mathrm{PI} 3 \mathrm{~K} / \mathrm{Akt}$ and NF-KB pathway. 
PCP-induced neurotoxic changes, and sociability deficits and recognition memory impairment. Modulation of the interaction between glutathione peroxidase (GPx) activity and PHOX (p47phox) is necessary for Re to exhibit its neuroprotective potential against PCP insult [85].

\section{Ginsenoside Rg1}

Various molecular studies have researched the pharmacological potential of ginsenoside Rg1 in cognitive impairment models. Rg1 treatment $(30 \mathrm{mg} / \mathrm{kg}$ i.p. for 10 days) improved chronic morphine-induced spatial learning capacity and restored the morphine-inhibited LTP. These effects were depended on N-methyl-d-aspartic acid (NMDA) receptor [86]. In a scopolamine-induced memory and learning impairment study, Rg1 (6 and $12 \mathrm{mg} / \mathrm{kg}$ i.p. for 7 days) improved ACh levels and inhibited AChE activity in the hippocampus and prevented the decrease of scopolamine-induced 5-HT [70]. In a D-galactose-induced impairment rat model, $\mathrm{Rg} 1$ treatment $(20 \mathrm{mg} / \mathrm{kg}$ i.p. for 28 days) displayed activity against memory impairment. It possibly attenuated all the D-galactose-induced changes in the hippocampus, such as cognitive capacity, senescencerelated markers, and hippocampal neurogenesis, compared to those that occurred in the untreated rats. Further investigation showed that Rg1 protects neural stem cells/ neural progenitor cells (NSCs/NPCs) as indicated by the elevated SOX-2 expression level, and reduces astrocyte activation, as indicated by the reduced astrocyte elevated gene-1 expression level. It also increases hippocampal cell proliferation and enhances the activity of the antioxidant enzymes GPx and SOD. Rg3-treatment decreased proinflammatory cytokines such as IL-1 $\beta$, IL-6, and TNF- $\alpha$, but, increased the telomere lengths and telomerase activity and downregulated the mRNA expression of cellular senescence-related genes p53, p21Cip1/Waf1, and p19Arf in the hippocampus of aged rats [87]. A mechanistic study showed that long-term administration of Rg1 supplement improved the performance of aged mice in a behavior test and significantly upregulated the expression of hippocampal synaptic plasticityassociated proteins such as synaptophysin, NMDA receptor subunit 1 (GluN1), postsynaptic density-95, and calcium/calmodulin-dependent protein kinase II alpha by promoting the activation of mTOR pathway [88]. In a chronic restraint stress (CRS) rat model, Rg1 ameliorated cognitive deficits, especially the loss of adaptation capacity. CRS decreases the levels of BDNF, tropomyosin receptor kinase $\mathrm{B}$ (TrkB), and ERK phosphorylation in the prefrontal cortex of CRS rats. However, these changes were effectively reversed by $\mathrm{Rg} 1$ (5 and $10 \mathrm{mg} / \mathrm{kg}$ i.p.) [89]. Rg1 also showed remarkable effects in isoflurane-, LPS- and dexamethasone-induced cognitive impairments in rodent models. Treatment with $\mathrm{Rg} 1$ (20 mg/kg for 7 days) significantly improved cognitive function and exhibited antioxidant and anti-inflammatory effects, demonstrating the neuroprotective effects of ginsenoside Rg1 against the effect of isoflurane anesthesia in the rats. In addition, it significantly reduced caspase- 3 activity, upregulated the expression of $\mathrm{PI} 3 \mathrm{~K} /$ protein kinase $\mathrm{B} /$ glycogen synthase-3 $\beta$, and downregulated the mRNA expression levels of p21WAF1/CIP1 and p53 in aged rats exposed to isoflurane anesthesia [90]. It has a protective effect against LPS-induced cognitive deficit and its prevention of LPS-induced changes in the cholinergic system is crucial to this ameliorating effect [91]. In a dexamethasone-induced cognitive impairment mice model, Rg1 (2 and $4 \mathrm{mg} / \mathrm{kg}$ ) treatment increased spontaneous motor activity and exploratory behavior in an open field test and increased the number of entries into the new object zone in a novel object recognition test. Moreover, Rg1 (2 and $4 \mathrm{mg} / \mathrm{kg}$ ) treatment significantly alleviated neuronal degeneration and increased microtubuleassociated protein 2 expression in the frontal cortex and hippocampus. Inhibition of NACHT, LRR and PYD domains-containing protein (NLRP) 1 inflammasomes was also involved in the mechanism underlying the effect of Rg1 on dexamethasone-induced neuronal injury [92]. Rg1 improved the postoperative survival rate and protected against sepsis-associated learning and memory impairment in a sepsis-associated encephalopathy model. It attenuated histopathologic changes in the brain, suppressed Iba1 activation, decreased the expression of inflammatory cytokines, including TNF- $\alpha$, IL-1 $\beta$, and IL-6, and reduced neuronal apoptosis (cleaved caspase 3 activation) in the hippocampus. Study of the mechanism of these effects by $\mathrm{Rg} 1$ showed that it suppressed the expressions of light chain 3eII and p62 in the hippocampus [93]. Rg1 (10 $\mathrm{mg} / \mathrm{kg}$ for 30 days) enhanced long-term memory in middle-aged mice. Consistent with the improvement in memory, ginsenoside Rg1 administration facilitated weak theta-burst stimulation-induced LTP in acute hippocampal slices from middle-aged mice and increased the dendritic apical spine numbers and area in the CA1 region. It is also upregulated the expression of hippocampal phospho-Akt, BDNF, proBDNF and glutamate receptor 1 (GluA1). Interestingly, the phosphatase and tensin homolog deleted from the chromosome 10 inhibitor bpV mimicked the effects of ginsenoside Rg1, including increasing p-Akt expression, and promoting hippocampal basal synaptic transmission, LTP, and memory [94]. Rg1 (10 mg/kg) suppressed the spontaneous neuronal activity of approximately $50 \%$ of the recorded-pyramidal cells in the medial prefrontal cortex. In addition, Rg1 attenuated LTP in the hippocampal-medial prefrontal cortical pathway in a rat model [95]. In addition to its use in various toxic agents-induced impairment models, Rg1 produced protective and cognitive-enhancing activities in a transgenic mouse model of $\mathrm{AD}$, which was constructed via the overexpression of APP and presenilin 1. Mice were treated with $0.1-10 \mathrm{mg} / \mathrm{kg}$ of $\mathrm{Rg} 1$ via intraperitoneal injection. Rg1 treatment (10 mg/ 
$\mathrm{kg}$ for 30 days) improved memory. As demonstrated by biochemical experiments, $\operatorname{Rg} 1$ reduced the accumulation of $\mathrm{A} \beta_{1-42}$ and phosphorylated (p)-Tau in the AD model. BDNF and $p$-TrkB synaptic plasticity-associated proteins were upregulated following administration of Rg1. Correspondingly, LTP was restored following administration of $\mathrm{Rg} 1$ in the AD mouse model [96]. In a molecular study using 3xTg-AD mice, Rg1 improved memory and ameliorated depression-like behaviors. Proteomic analysis revealed that downregulation of complexin-2, synapsin-2, and synaptosomal-associated protein 25 in the hippocampus of $3 \times \mathrm{Tg}$-AD mice was significantly greater than that in compared with the WT mice, and Rg1 treatment modulated the expression of complexin-2 and synaptosomal-associated protein 25 in the hippocampus of $3 \times \mathrm{Tg}-\mathrm{AD}$ mice [97]. The potential therapeutic activities of ginsenoside $\mathrm{Rg} 1$ in various models of cognitive impairment are presented in Table 1.

\section{Ginsenosides Rg2 and Rg3}

In a vascular dementia (VM) rat model, ginsenoside $\mathrm{Rg} 2$ protected against memory impairment via an antiapoptotic mechanism. VM decreased expression of Bcl2 and the heat shock protein 70, while increasing Bax and P53. After ginsenoside $\operatorname{Rg} 2(2.5,5$ and $10 \mathrm{mg} / \mathrm{kg})$ treatment, the expression of $\mathrm{Bcl}-2$ and heat shock protein 70 increased and Bax and P53 decreased compared with the expression levels in the VM-only group [98].

Ginsenoside Rg3 had effects in both scopolamineand LPS-induced memory impairment in models [99-101] In the scopolamine-induced memory impairment mouse model, $\operatorname{Rg} 3$ [50 and $100 \mathrm{mg} / \mathrm{kg}$, per oral (p.o.)] suppressed the scopolamine-mediated increase in $\mathrm{AChE}$ activity and stimulation of the NF- $\mathrm{kB}$ pathway (i.e., phosphorylation of p65) in the hippocampus [100]. In addition, administration of $\operatorname{Rg} 3(10,20$, and $50 \mathrm{mg} / \mathrm{kg}$, i.p.) for 21 consecutive days markedly reduced the LPS-induced learning and memory impairment in rat behavioral studies. It significantly decreased the expression of proinflammatory mediators such as TNF- $\alpha$, IL- $1 \beta$, and COX-2 in the hippocampus [99]. In a recent study, Rg3 prevented $\mathrm{H}_{2} \mathrm{O}_{2}$-induced astrocytic senescence and ameliorated the paracrine effects of senescence on glioblastoma. Rg3 (5 $\mu \mathrm{g} / \mathrm{ml}$ ) effectively prevented the astrocytic senescence induced by $\mathrm{H} 2 \mathrm{O} 2$ exposure. $\mathrm{Rg} 3$ treatment at $10 \mu \mathrm{g} /$ $\mathrm{ml}$ effectively suppressed the expressions of IL-6 and IL-8, which is associated with regulation NF- $\kappa B$ and p38MAPK activation. In addition, after incubation with $\mathrm{Rg} 3$, the conditioned medium from senescent astrocytic CRT cells significantly decreased the ability to promote the proliferation of astrocytoma U373-MG, U87MG, and U251-MG cells compared with nontreated senescent samples. Similar patterns were confirmed in chemotherapy-induced senescent glioblastoma cells [102]. Additionally, Rg3 restored proliferation and inhibited apoptosis by altering the cell cycle in NMDA-treated HT22 murine hippocampal neuronal cells. It improved the change in physiological behavior in a chronic mild stress model, as seen in forced swim, tail suspension, and sucrose preference tests. The effects were facilitated by the phosphorylation of cAMP response element-binding protein (CREB) and BDNF signaling [103]. The activity of biodegradable poly(lactic-co-glycolic acid)-ginsenoside Rg3 nanoformulation in an AD model was described in a recent article [104]. This nanoformulation reduced $\mathrm{A} \beta$ plaques and downregulated $\beta$-amyloid $\mathrm{A} 4$ precursor protein (A $\beta \mathrm{PP}-\mathrm{A} 4)$ gene expression levels and produces neuroprotection. The neuroprotective activity of this novel formulation results from the prevention of oxidative stress and mitochondrial dysfunction.

\section{Ginsenosides Rh1, Rh2 and Rh3}

In a scopolamine-induced cognitive impairment rodent model, ginsenoside $\mathrm{Rh} 1$ and $\mathrm{Rh} 3$ have a negative effect against impairment. In rat behavioral studies, $\mathrm{Rh} 1(5$ and $10 \mathrm{mg} / \mathrm{kg})$ and $\mathrm{Rh} 3(10 \mathrm{mg} / \mathrm{kg})$ ameliorated scopolamine-induced memory impairment $[105,106]$. Rh1 increased hippocampal excitability in the dentate gyrus [105]. It significantly enhanced cell survival in the dentate gyrus of mice and upregulated BDNF expression [107]. In a recent study, Rh1 had a beneficial effect against sleep deprivation-induced cognitive impairment in mice. In addition, the ability Rh1 $(20 \mu \mathrm{M} / \mathrm{kg}$ and 40 $\mu \mathrm{M} / \mathrm{kg}$ for 23 days) reduce oxidative stress in the cortex and hippocampus that might be involved in the mechanism of action [108]. Moreover, Rh2 (10 mg/ml for 3 weeks) significantly improved spatial learning and memory and promoted cell survival and genesis [109]. Like $\mathrm{Rh} 1$ and $\mathrm{Rh} 2$, ginsenoside $\mathrm{Rh} 3$ has a protective effect against cognitive impairment and also inhibits AChE activity in a dose-dependent manner. Besides, Rh3 also reversed hippocampal BDNF expression and reduced the phosphorylation of CREB in scopolamine-induced cognitive impairment mice [106].

\section{Pseudoginsenoside-F11}

PF11 produces cognitive-enhancing activities in both scopolamine- and morphine-induced cognitive impairment rodent models. PF11 (2 and $4 \mathrm{mg} / \mathrm{kg}$ ) antagonized scopolamine-induced memory dysfunction in both mice and rats. In addition, in the morphine-induced cognitive impairment mice model, PF11 (4 and $8 \mathrm{mg} / \mathrm{kg}$ ) improved the behavioral responses of mice in the Morris water maze test and antagonized the development of analgesia tolerance to morphine in the tail pinch test $[110,111]$. A recent mechanistic study showed that PF11 $(8 \mathrm{mg} / \mathrm{kg})$ inhibited METH-induced hyperlocomotion, preference, and an increase in accumbal extracellular dopamine by regulating GABAergic neurons and $\mu$-opioid receptors 
Table 1: Activity of ginsenoside Rg1 in different models of cognitive deficits

\begin{tabular}{l} 
Model \\
\hline Morphine-induced \\
memory impairment \\
in rats \\
Scopolamine-induced \\
memory deficits in \\
mice \\
D-Galactose-induced \\
memory impairment \\
in rats
\end{tabular}

Dose
$30 \mathrm{mg} / \mathrm{kg}$ i.p. for 10 days
6 and $12 \mathrm{mg} / \mathrm{kg}$, i.p. for 7
days
$20 \mathrm{mg} / \mathrm{kg}$ i.p., for 28 days

Key effects
Improves spatial learning capacity and
restores LTP, and effect was NMDA receptor
dependent

Improves ACh levels and inhibits AChE activity in the hippocampus; prevents the decrease of scopolamine-induced 5-HT

References

Protects NSCs/NPCs by elevating SOX2 expression level; reduces astrocyte activation indicated by decreasing Aeg-1 expression level; increases the hippocampal cell proliferation and enhances the activity of the antioxidant enzymes GPx and SOD; decreases the pro-inflammatory cytokines but increases telomere lengths and telomerase activity; down-regulates mRNA expression of cellular senescence related genes p53, p21Cip1/Waf1 and p19Arf in hippocampus of aged rats

Age-Related Cognitive $6 \mathrm{mg} / \mathrm{kg}$ p.o. every third day Decline in C57BL/6J mice

Upregulates expression of hippocampal synaptic plasticity-associated proteins such as synaptophysin, N-methyl-D-aspartate receptor subunit 1 , postsynaptic density-95, and calcium/calmodulin-dependent protein

kinase II alpha, through promoting the activation of mTOR pathway

Chronic restraint stress in rat

Isoflurane-induced memory impairment in rat

LPS-induced cognitive deficit in rat

Dexamethasoneinduced memory impairment in mice

5 and $10 \mathrm{mg} / \mathrm{kg}$ i.p. for 24 days

$20 \mathrm{mg} / \mathrm{k}$, i.p. for 7 days

$200 \mathrm{mg} / \mathrm{kg}$ for 30 days

Sepsis-associated encephalopathy in mice 2 and $4 \mathrm{mg} / \mathrm{kg}$ p.o. for
28 days

40 and $200 \mathrm{mg} / \mathrm{kg} 10 \mathrm{ml} / \mathrm{kg}$ i.p. $1 \mathrm{~h}$ before operation

Ameliorates decrease in levels of BDNF, TrkB and ERK phosphorylation in prefrontal cortex

Reduces caspase-3 activity; upregulates the expression of PI3K/Akt/GSK-3 $\beta$; downregulates mRNA expression levels of p21WAF1/CIP1 and p53

Prevents decrease in ACh levels and increase of AChE activity; revert decrease of $\alpha 7$ $\mathrm{nAChR}$ protein expression in prefrontal cortex and hippocampus

Increases expression of glucocorticosteroid receptor and decreases expression of NLRP1, ASC, caspase-1, caspase-5, IL-1 $\beta$ and IL-18 in hippocampus

Attenuates brain histopathologic changes, suppresses Iba1 activation; decrease expression of inflammatory cytokines, including TNF- $\alpha$, IL-1 $\beta$, and IL-6; reduces neuronal apoptosis (cleaved caspase 3 activation) in hippocampus; suppresses the expressions of light chain 3-II and p62 in hippocampus

(Continued) 


\begin{tabular}{|c|c|c|c|}
\hline Model & Dose & Key effects & References \\
\hline $\begin{array}{l}\text { Theta-burst } \\
\text { stimulation-induced } \\
\text { LTP in mice }\end{array}$ & $\begin{array}{l}0.1,1 \text { or } 10 \mathrm{mg} / \mathrm{kg} \text { i.p. once a } \\
\text { day for } 30 \text { consecutive days }\end{array}$ & $\begin{array}{l}\text { Facilitates hippocampal basal synaptic } \\
\text { transmission and LTP; up-regulates } \\
\text { hippocampal BDNF and p-Akt expression; } \\
\text { increases hippocampal dendritic spines }\end{array}$ & {$[94]$} \\
\hline LTP in rat & $\begin{array}{c}1,3, \text { or } 10 \mathrm{mg} / \mathrm{kg} \text { systemic } \\
\text { administration }\end{array}$ & $\begin{array}{c}\text { Impairs LTP in HP-mPFC pathway, perhaps } \\
\text { by suppressing the firing of a subset of } \\
\text { mPFC neurons }\end{array}$ & {$[95]$} \\
\hline $\begin{array}{l}\text { Overexpression of } \\
\text { APP and PS1 in mice }\end{array}$ & $0.1-10 \mathrm{mg} / \mathrm{kg}$ i.p. for 30 days & $\begin{array}{l}\text { Repairs hippocampal LTP and memory, } \\
\text { likely through facilitating the clearance of } \\
\text { AD-associated proteins and activation of } \\
\text { BDNF-TrkB pathway }\end{array}$ & [96]. \\
\hline 3xTg-AD mice & $20 \mathrm{mg} / \mathrm{kg}$ i.p. for 6 weeks & $\begin{array}{l}\text { Improves behavioral deficits in AD via } \\
\text { modulating expression of proteins (i.e., } \\
\text { CPLX2, SYN2, and SNP25). }\end{array}$ & {$[97]$} \\
\hline
\end{tabular}

[112]. Moreover, PF11 produced cognitive enhancing effects in both $\mathrm{A} \beta_{1-42}$-induced and Tg-APPswe/PS1dE9 (APP/PS1) mouse AD models and in 6-hydroxydopamine (6-OHDA)-induced Parkinson's disease model [113, 114]. In AD mouse models, PF11 treatment at doses of 1.6 and $8 \mathrm{mg} / \mathrm{kg}$ for 15 days significantly mitigated $\mathrm{A} \beta_{1-42}$-induced learning and memory impairment and PF11 treatment at a dose of $8 \mathrm{mg} / \mathrm{kg}$ for 4 weeks $8 \mathrm{mg} / \mathrm{kg}$ dose for 4 weeks improved memory in APP/PS1 mice in behavioral studies. In the APP/PS1 mice, PF11 significantly inhibited the expressions of APP and $A \beta_{1-40}$ in the cortex and hippocampus, restored the activities of SOD and GPx, and decreased the production of malondialdehyde in the cortex. It also noticeably improved the histopathological changes in the cortex and hippocampus and downregulated the expressions of JNK2 p53 and cleaved caspase 3 in the hippocampus [113]. In a 6-OHDA-induced PD rat model, PF11 (3, 6, and $12 \mathrm{mg} / \mathrm{kg})$ markedly improved the locomotion, motor balance, coordination, and apomorphine-induced rotation skills in rats. PF11 treatment increased the expression of $\mathrm{TH}$ in the substantia nigra and also significantly increased the content of extracellular dopamine in the striatum. Compared with the 6-OHDA-lesioned group, PF11 treatment significantly reduced in the levels of striatal extracellular hydroxyl radical $(\cdot \mathrm{OH})$, detected as 2,3- and 2,5-dihydroxy benzoic acid (DHBA), and increased the level of striatal extracellular ascorbic acid [114]. Furthermore, PF11 had a neuroprotective effect against permanent middle cerebral artery occlusion (pMCAO) in rats. One $12 \mathrm{mg}$ / $\mathrm{kg}$ dose of PF11 significantly decreased the infarct area, reduced brain water content, and improved neurological functions, even $4 \mathrm{~h}$ after the onset of pMCAO. PF11 lessened the ischemic insult-mediated loss of neurons and the activation of astrocytes and microglia and it attenuated pMCAO-induced accumulations of autophagosomes and apoptosis. In addition, PF11 had a remarkable effect in reversing the ischemic insult-induced accumulation of autophagosomes (LC3-II) and abnormal aggregation of autophagic proteins (SQSTM1 and ubiquitin). It was capable of improving lysosomal function and lysosome/ autophagosome fusion following pMCAO. This change was reversed by the lysosomal inhibitor chloroquine, which, in turn reversed improvement in ischemic outcome and the antiapoptotic effect [115].

\section{Notoginsenoside R1}

Several molecular studies have noted the effect of notoginsenoside R1 (NTR1) on cognitive impairment. Treatment with $10 \mu \mathrm{M}$ NTR1 protected cells expressing the NR1/NR2B subunit from the NMDA-induced cell death in primary cultured mouse cortical neurons [116]. In an $\mathrm{A} \beta$-induced $\mathrm{AD}$ model, $10 \mu \mathrm{M}$ dose significantly counteracted the effects of $A \beta$ by increasing cell viability, reducing oxidative damage (including apoptosis), restoring mitochondrial membrane potential, and suppressing stressactivated MAPK signaling pathways [117]. In another study, NTR1 increased the membrane excitability of CA1 pyramidal neurons in hippocampal slices by lowering the spike threshold possibly via a mechanism that involves the inhibition of voltage-gated $\mathrm{K}^{+}$currents. NTR1 also reversed $\mathrm{A} \beta_{1-42}$-induced impairments in LTP. Reduction of spontaneous firing activity with $10 \mathrm{nM}$ tetrodotoxin abolished the protective effect of NTR1 against A $\beta$-induced LTP impairment. Finally, oral administration of NTR1 improved the learning performance of APP/PS1 mice in the AD model [118]. Oral administration of 5 and $25 \mathrm{mg} /$ kg NTR1 significantly ameliorated cognitive function and increased the expression of choline acetyl transferase, as compared to vehicle-treated mice. Furthermore, NTR1 treatment inhibited $A \beta$ accumulation and increased the expression of insulin degrading enzyme in both APP/PS1 mice and N2a-APP695sw cells, suggesting that NTR1 
may exert its protective effects through the enhancement of the A $\beta$ degradation. It increased the level of PPAR $\gamma$ and the up-regulation of insulin-degrading enzyme induced by NTR1 was inhibited by administration of GW9662 (a PPAR $\gamma$ antagonist), indicating that the effect of NTR1 was mediated, in part, by PPAR $\gamma$ [119]. In a diabetic encephalopathy model, administration of 10 and $30 \mathrm{mg} / \mathrm{kg}$ NTR1 for 10 weeks ameliorated cognitive dysfunction, depression-like behaviors, insulin resistance, hyperinsulinemia, dyslipidemia, and inflammation in $\mathrm{db} /$ $\mathrm{db}$ mice. NTR1 $(20 \mu \mathrm{M})$ markedly decreased the oxidative stress induced by hyperglycemia in hippocampal neurons. NTR1 significantly activated the Akt/Nrf2 pathways and inhibited NLRP3 inflammasome activation in hippocampal neurons, which might be essential with respect to the neuroprotective effects of NTR1. Pretreatment with the phosphatidylinositol 3-kinase (PI3K) inhibitor LY294002 negated the neuroprotective effects of NTR1 against oxidative stress and NTR1-mediated NLRP3 inflammasome activation in high glucose-treated HT22 hippocampal neurons [120]. The proposed activities of NTR1 against cognitive impairment are presented in Figure 3.

\section{Gintonin}

In a recent study, gintonin produced activity against cognitive impairment in a mice model. Oral administration of $50 \mathrm{mg} / \mathrm{kg}$ gintonin for 1 week significantly improved behavioral functions in the contextual fear-conditioning test. Gintonin treatment increased the expression of learning and memory-related proteins such as the phosphorylated CREB protein and BDNF and gintonin administration enhanced LTP in the hippocampus [121]. In another study, gintonin played a role in $\mathrm{SA} \beta \mathrm{PP} \alpha$ release, $\mathrm{A} \beta$ formation, Swedish-A $\beta P P$ transfection-mediated neurotoxicity in SH-SY5Y neuroblastoma cells, and A $\beta$ induced neuropathy in mice. It mediated the promotion of non-amyloidogenic processing to stimulate $\mathrm{sA} \beta \mathrm{PP} \alpha$ release to restore brain function in mice with $\mathrm{AD}$ [122]. Another report described the effect of gintonin on an $A \beta-$ induced cognitive impairment model where by at the doses of 25 or $50 \mathrm{mg} / \mathrm{kg}$ for 2 weeks, attenuated $\mathrm{A} \beta$-induced cholinergic dysfunctions. Gintonin treatment increased ACh concentration, choline acetyltransferase activity, and immunoreactivity, but it decreased AChE activity. In addition to $\mathrm{A} \beta$-induced impairment model, long-term oral administration of gintonin ( 25 or $50 \mathrm{mg} / \mathrm{kg}$ for 3 months) showed potential activity in a transgenic AD mouse model. It also attenuated AD-related cholinergic impairment in that model [123]. Lysophosphatidic acid (LPA) is a wellcharacterized and ubiquitous phospholipid molecule that produced effect by activating $\mathrm{G}$ protein-coupled receptors known as LPA receptors (LPARs). During the early stages of development, LPAR signaling is critically involved in the regulation of synapse formation and the morphology

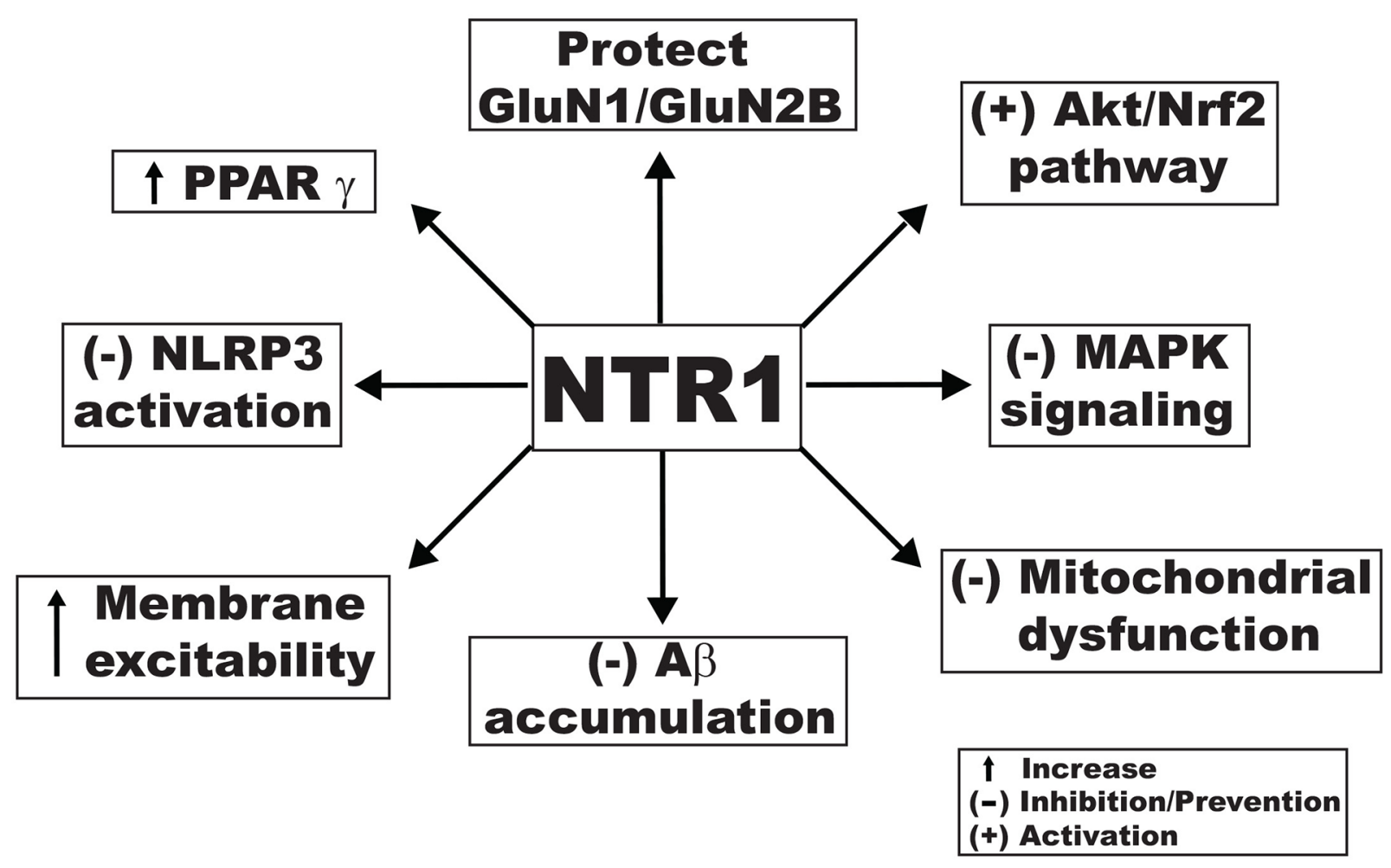

Figure 3: Proposed mechanistic activities of notoginsenoside R1 against cognitive impairment produced through different signaling pathways. 
of cortical and hippocampal neurons. Moreover, LPARs seem to contribute to cognitive as well as emotional learning and memory in adult brains [124]. As a ligand, gintonin activates LPAR with high affinity [122, 125] and activates $\mathrm{Ca}^{2+}$-activated $\mathrm{Cl}$ channels in Xenopus oocytes by activating LPAR. Gintonin mediation of INMDA potentiation and LTP induction in the hippocampus via the activation of LPAR might account for ginsengmediated improvement of memory-related brain functions [125]. Furthermore, gintonin induced $\left[\mathrm{Ca}^{2+}\right]_{\mathrm{i}}$ transients in cultured mouse hippocampal neural progenitor cells (NPCs). These $\left[\mathrm{Ca}^{2+}\right]_{\mathrm{i}}$ transients were linked to stimulation of ACh release through LPAR activation [123]. The gintonin mediated LPAR activation vastly improved both excitatory and inhibitory transmission in central synapses and resulted in synaptic enhancement and an increase in neuronal excitability in a phospholipase C-dependent manner [124]. Gintonin increased the incorporation of 5-bromo-2'-deoxyuridine (BrdU) in hippocampal NPCs in a dose- and time-dependent manner. At $0.3 \mu \mathrm{g} / \mathrm{ml}$, gintonin increased the immunostaining of glial fibrillary acidic protein, NeuN, and LPA1 receptor in hippocampal NPCs. However, as an LPA1/3 receptor antagonist and $\mathrm{Ca}^{2+}$ chelator block, gintonin induced an increase in BrdU incorporation and immunostaining of biomarkers. Oral administration of a gintonin-enriched fraction (50 and $100 \mathrm{mg} / \mathrm{kg}$ ) increased hippocampal BrdU incorporation and LPA $1 / 3$ receptor expression in adult wild-type and transgenic AD mice [126].

\section{Compound K}

In the cyclophosphamide-induced cognitive impairment mice model, compound $\mathrm{K}$ activity acts against cognitive impairment. Cognitive deficits an adverse effect of the chemotherapeutic agent, but 4 weeks treatment with compound $\mathrm{K}(2.5,5$ and $10 \mathrm{mg} / \mathrm{kg})$ improves memory. Moreover, compound $\mathrm{K}(10 \mathrm{mg} / \mathrm{kg})$ ameliorates the cyclophosphamide-induced decrease of neurogenesis in the hippocampus [127]. A recent study showed that it improved memory function in cyclophosphamide-induced and glutamate-induced cytotoxicity in hippocampal HT22 cells. Compound K ( $8 \mu \mathrm{M})$ induced antioxidant enzymes in an Nrf2-mediated manner and effectively attenuated cytotoxicity and mitochondrial damage induced by glutamate in HT22 cells. However, tin protoporphyrin IX (heme oxygenase-1 inhibitor) negated the cytoprotective effect of compound K. Therefore, Nrf2-mediated induction of antioxidant enzymes might involve in neuroprotective effect of compound $\mathrm{K}$. In addition, compound K (10 $\mathrm{mg} / \mathrm{kg}$ ) enhanced learning and memory performance in $\mathrm{C} 57 \mathrm{BL} / 6$ mice used in a scopolamine-induced model [128]. In an LPS-induced neuroinflammation model, compound $\mathrm{K}$ inhibited the expression of iNOS, proinflammatory cytokines, monocyte chemotactic protein-1, matrix metalloproteinase-3, and matrix metalloproteinase-9 in both BV-2 microglial cells and primary cultured microglia. Compound $\mathrm{K}$ suppressed microglial activation by inhibiting the activities of ROS, MAPK, and NF- $\mathrm{B}$ /activator protein-1 via the enhancement of heme oxygenase-1/antioxidant response element signaling. Based on its effect on microglia, compound $\mathrm{K}$ also reduces the number of Iba1-positive activated microglia and inhibits the expression of TNF- $\alpha$ and IL-1 $\beta$ in the brains with LPS-induced sepsis. Compound $\mathrm{K}$ also reduces the infarct volume of ischemic brain induced by pMCAO and suppresses microglial activation in the ischemic cortex [129]. In addition to its effect on microglia, compound $K$ enhances $A \beta$ clearance by increasing autophagy via the mTOR signaling pathway in primary astrocytes [130]. The potential activities of compound $\mathrm{K}$ against cognitive impairment are presented in Figure 4.

\section{PROSPECTS FOR DELIVERY AND CLINICAL STUDY OF GINSENG COMPONENTS FOR COGNITIVE IMPAIRMENT}

Although clinical studies on ginseng have been performed, the effect of individual active ginseng components in cognitive impairment has not been studied. Of the various ginseng species, Korean and American ginsengs have been studied for their clinical efficacies. Korean ginseng increases cognitive performance in AD patients $[18,131]$. One study included volunteers $(n=58)$ treated with ginseng powder (4.5-g/day) for 12 weeks and untreated control group $(n=39)$. The Alzheimer disease Assessment Scale cognitive subscale (ADAS-cog) and the mini-mental state examination (MMSE) score began to show improvement up to 12 weeks after ginseng treatment. The improvement in the ADAS-cog and MMSE declined to the levels of the control group after the discontinuation of ginseng treatment [131]. After confirming the cognitive benefits of $P$. ginseng's in AD patients in a 24-week randomized open-label study, treatment continued for up to two years to further determine its long-term effect. While the subjects took 4.5 or $9.0 \mathrm{~g} P$. ginseng per day, cognitive function was evaluated every 12 weeks using the ADAS-cog and MMSE. There was a significant improvement in both ADAS-cog and MMSE scores of the $P$. ginseng-treated groups at 24 weeks [18]. Other studies confirmed the cognitive-enhancing activity of Korean ginseng $[132,133]$. In a study of healthy volunteers $(n=15)$ without impairments, Korean ginseng had a cognitiveenhancing effect in the treatment group (4500 $\mathrm{mg}$ daily) in compared with the placebo group [132]. In another study, $P$. ginseng had a cognitive-enhancing effect in healthy volunteers $(n=90)$ with mild cognitive impairments. The subjects in the ginseng-treated group showed significant improvement on the visual learning test and the visual 
recall test after 6 months of $P$. ginseng treatment compared with the placebo group [133]. American ginseng at 100, 200 and $400 \mathrm{mg}$ also had cognitive-enhancing effects in a randomized, double-blind, placebo-controlled, crossover study of healthy young adults $(n=32)$. The working memory performance and Corsi block performance of the treated group improved. Moreover, choice reaction time accuracy and calmness significantly improved with the $100 \mathrm{mg}$ treatment [134]. In another study, HT1001, a standardized proprietary $P$. quinquefolius extract containing Rb1, Rg1 and other important ginsenosides was administered (dose $=200 \mathrm{mg}$ ) to healthy volunteers who were divided into two groups: a young adult sample $(n=10)$ and a middle-aged sample $(n=10)$. Study found that HT1001 might be a candidate for further clinical study on learning and memory [135].

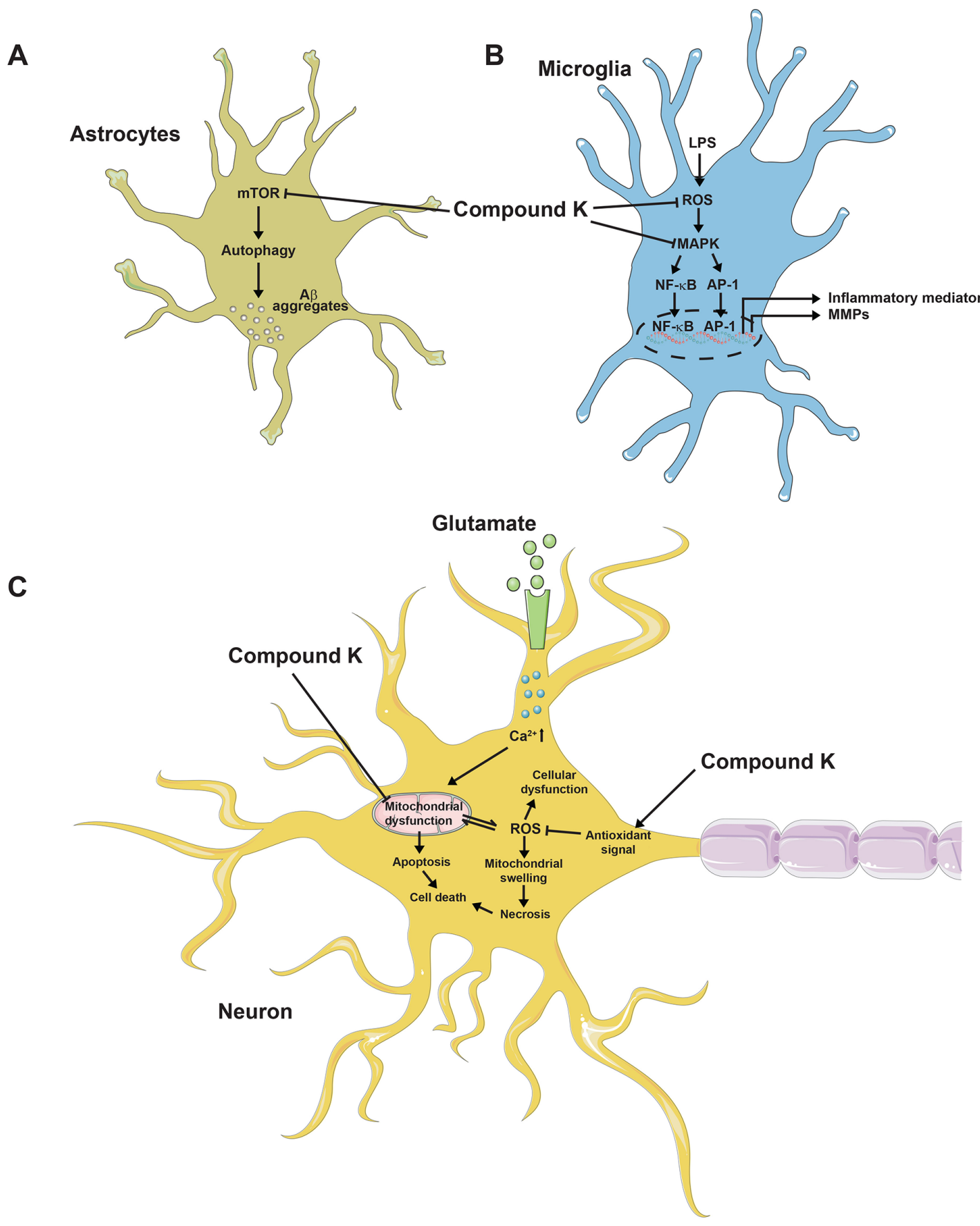

Figure 4: Probable activities of compound $\mathrm{K}$ against cognitive impairment. (A) Compound $\mathrm{K}$ inhibits mTOR pathway in astrocyte, leading to autophagy-dependent A $\beta$ clearance. (B) Compound K produces anti-inflammatory activity in microglia by inhibiting ROS generation and MAPK pathway. (C) Compound $\mathrm{K}$ prevents mitochondrial dysfunction and activates antioxidant signal in neurons, possibly leading to protective activity against cell death. 
The therapeutic potential of ginsenosides has been limited mostly by low-bioavailability that is caused by low aqueous solubility, poor bio-membrane permeability, instability in the gastrointestinal tract, and extensive metabolism in the body [136]. Several experiments using formulated ginsenoside nanoparticles have been conducted. PLGA-encapsulated ginsenoside Rg3 increased antitumor activity [137]. Bovine serum albumin (BSA)-Rh2 nanoparticle (NP) formulation has improved solubility and stability and has enhanced anticancer and anti-inflammatory effects in cell lines [138]. In addition to a nanoparticle delivery system, some of studies have focused on liposome for delivery. Compound K-loaded liposomes modified with D- $\alpha$-tocopheryl polyethylene glycol 1000 succinate (TPGS) (GCKT-liposomes) have enhanced solubility and show significant antitumor activity [139]. Among the three formulations of Rh2loaded liposomes, i.e., Rh2-loaded normal liposome, $\mathrm{Rh} 2$-loaded cationic liposome, and Rh2-loaded methoxy poly(ethylene glycol)-polylactide (mPEG-PLA) liposome, the latter might be promising way to enhance the therapeutic index of anticancer agents [140]. Moreover, a liposomal formulation of $\mathrm{Rg} 3$ might improve anticancer activity [141]. Considering the pharmacokinetic behavior, many recent studies have focused on its novel formulation and delivery. Few studies have focused on intranasal delivery of active ginseng components as a way to target the brain. Ginsenosides Rg1 and Rb1 in Nao-Qing microemulsion promoted absorption and achieved a fast effect in an acute ischemic stroke model [142]. In another study, intranasal delivery of Rb1 exerted brain-targeting effects and ameliorated ischemia/reperfusion insult immediately after MACAO. Autophagy was involved in these beneficial effects [143]. Rg1 nanoparticles were developed to overcome the blood-brain barrier (BBB)mediated restriction of $\operatorname{Rg} 1$ to reach the CNS. At a high concentration, $\operatorname{Rg} 1$ nanoparticles can penetrate the $\mathrm{BBB}$ to reduce the cerebral infarction volume and promote neuronal recovery in vivo [144]. In addition, nanoparticle formulation of $\mathrm{Rg} 3$ offered neuroprotective activity in an $\mathrm{AD}$ model. This formulation is biodegradable and has minimal side effects giving it potential for AD therapy [104].

Setting up a clinical study of the use of different ginseng species for treating cognitive deficits is a major challenge in ginseng research. Second, conducting a clinical study on active ginseng components in a designed cognitive impairment model is recommended. Third, novel formulations of active ginseng constituents are candidates for preclinical and clinical models of cognitive impairment.

\section{CONCLUDING REMARKS}

Ginseng has long been used as a traditional medicine in many countries because of its high therapeutic value.
It displays beneficial roles against various diseases and disorders. In neurological disease model, ginseng and its active components show the potential for pharmacological activity. In the present article, we reviewed the therapeutic potential of its active constituents in cognitive impairment, along with modes of delivery and challenges concerning clinical studies. Active ginseng constituents, including ginsenosides Rb1, Rd, Re, Rg1, Rg2, Rg3, Rh1, Rh2, Rh3, PF11, and NTR1, and gintonin and compound $\mathrm{K}$ have shown potential activity in treating cognitive deficits. They produced effects in both cellular and animal model studies. Different animal models used for behavioral studies have been postulated to study the effects of ginseng and its active components on cognitive impairment induced by different well-known neurotoxic agents. Moreover, studies based on biochemistry, molecular biology, and histochemistry confirmed their possible therapeutic activity against cognitive impairment. In addition to animal models, several studies have focused on cellular models to prove the potential of ginseng and its active components. The studies have also shown possible pharmacological activity produced by ginseng and its components. In both animal and cellular model studies, they produced activity against oxidative stress leading to cognitive-enhancing function. Apart from oxidative stress, many active components produce anti-neuroinflammatory agents that might be associated with their activities in cognitive impairment. More importantly, our data has shown that several ginseng constituents exert their effects by modulating cholinergic, glutaminergic, and other molecular signaling pathways that are vital for cognitive activity.

Numerous recent studies have reported on the potential therapeutic efficacy of active ginseng components, but more studies utilizing novel techniques are needed. The effect of active components should be confirmed at the molecular level using a preclinical study focused on transgenic and toxin-induced wild-type animal models. In both animal and cellular model studies, knockout and knockdown animal models should be used to focus on molecular signals associated with cognition. Finally, because of the small number of studies on active ginseng components, we recommend the design and performance of experiments with ginseng constituents and their analogues in novel formulations for treating cognitive deficits at the clinical level.

\section{Abbreviations}

5-HT: 5-hydroxytryptamine; 5-HT: 5-hydroxytryptamine; 6-OHDA: 6-Hydroxydopamine; ACh: Acetylcholine; AChE: Acetylcholinesterase; AD: Alzheimer's disease; Aeg-1: Astrocyte elevated gene1; Akt: Protein kinase B; APP: Amyloid $\beta$-protein precursor; ASC: Antibody secreting cells; A $\beta$ : Amyloid beta; Bax: Bcl-2-like protein 4; Bcl-2: B-cell lymphoma 
2; BDNF: Brain-derived neurotrophic factor; BrdU: 5-Bromo-2'-deoxyuridine; CPLX2: Complexin-2; CREB: cAMP response element-binding protein; CRS: Chronic restraint stress; ERK: Extracellular signalregulated kinase; GPx: Glutathione peroxidase; GSH: Glutathione; GSK-3ß: Glycogen synthase kinase 3; HP-mPFC: hippocampal-medial prefrontal cortex; i.p.: Intraperitoneal; Iba1: Ionized calcium-binding adapter molecule 1; IL: Interleukin; JNK: c-Jun N-terminal protein kinase; LPA: Lysophosphatidic acid; LPAR: LPA receptor; LPS: Lipopolysaccharide; LTP: Longterm potentiation; MAPK: Mitogen-activated protein kinase; mTOR: Mammalian target of rapamycin; NF- $\mathrm{B}$ : Nuclear factor kappa-light-chain-enhancer of activated B cells; NLRP: NACHT, LRR and PYD domainscontaining protein; NMDA: $N$-methyl-D-aspartic acid; Nrf2: Nuclear factor (erythroid-derived 2)-like 2; NSCs/NPCs: Neural stem cells/neural progenitor cells; NTR1: Notoginsenoside R1; p-Akt: PhosphoAkt; p.o.: Per oral; PF11: Pseudoginsenoside-F11; PI3K: Phosphatidylinositol-3 kinase; PI3K: Phosphatidylinositol-3 kinase; pMCAO: Permanent middle cerebral artery occlusion; PPAR $\gamma$ : Peroxisome proliferator-activated receptor; $\gamma$ PPD: Protopanaxadiol; PPT: Protopanaxatriol; PS1: Presenilin-1; sAPP $\alpha$ : Secreted amyloid precursor protein- $\alpha$ SNP25: Synaptosomal-associated protein 25.; SOD: Superoxide dismutase; SOX-2: SRY (sex determining region Y)box 2; SYN2: Synapsin II; SOD: superoxide dismutase; TNF- $\alpha$ : Tumor necrosis factor- $\alpha$ TrkB: Tropomyosin receptor kinase $\mathrm{B}$; $\alpha 7$ nAChR: Alpha-7 nicotinic receptor.

\section{Author contributions}

MJ and DKC conceived and designed the study. MJ performed literature review, wrote the manuscript, produced the figures and compiled the table. MEH, DYC and JK arranged the data, and ISK arranged the data and drew the figures. DKC also supervised and handled correspondence. All authors read and approved the final manuscript.

\section{ACKNOWLEDGMENTS}

This research was supported by The Leading Human Resource Training Program of Regional Neo Industry through the National Research Foundation of Korea (NRF), funded by the Ministry of Science, ICT and Future Planning (Grant no. NRF-2016H1D5A1909610). This paper was also written as part of Konkuk University's research support program for its faculty on sabbatical leave in 2017.

\section{CONFLICTS OF INTEREST}

The authors have no conflicts of interest to declare.

\section{REFERENCES}

1. Kim HJ, Kim P, Shin CY. A comprehensive review of the therapeutic and pharmacological effects of ginseng and ginsenosides in central nervous system. J Ginseng Res. 2013; 37:8-29.

2. Rokot NT, Kairupan TS, Cheng KC, Runtuwene J, Kapantow NH, Amitani M, Morinaga A, Amitani H, Asakawa A, Inui A. A Role of Ginseng and Its Constituents in the Treatment of Central Nervous System Disorders. Evid Based Complement Alternat Med. 2016; 2016:2614742. https://doi.org/10.1155/2016/2614742.

3. Lu G, Zhou Q, Sun S, Leung KS, Zhang H, Zhao Z. Differentiation of Asian ginseng, American ginseng and Notoginseng by Fourier transform infrared spectroscopy combined with two-dimensional correlation infrared spectroscopy. J Mol Struct. 2008; 883:91-98.

4. Ong WY, Farooqui T, Koh HL, Farooqui AA, Ling EA. Protective effects of ginseng on neurological disorders. Front Aging Neurosci. 2015; 7:129.

5. Ge W, Li H, Zhao Y, Cai E, Zhu H, Gao Y, Liu S, Yang H, Zhang L. Study on antidepressant activity of sesquiterpenoids from ginseng root. J Funct Foods. 2017; 33:261-67.

6. Kim EH, Kim IH, Ha JA, Choi KT, Pyo S, Rhee DK. Antistress effect of red ginseng in brain cells is mediated by TACE repression via PADI4. J Ginseng Res. 2013; $37: 315-23$.

7. Lian XY, Zhang ZZ, Stringer JL. Anticonvulsant activity of ginseng on seizures induced by chemical convulsants. Epilepsia. 2005; 46:15-22.

8. Chatterjee M, Singh S, Kumari R, Verma AK, Palit G. Evaluation of the antipsychotic potential of Panax quinquefolium in ketamine induced experimental psychosis model in mice. Neurochem Res. 2012; 37:759-70.

9. Clare L, Wu YT, Teale JC, MacLeod C, Matthews F, Brayne C, Woods B, and CFAS-Wales study team. Potentially modifiable lifestyle factors, cognitive reserve, and cognitive function in later life: A cross-sectional study. PLoS Med. 2017; 14:e1002259.

10. Amieva H, Meillon C, Helmer C, Barberger-Gateau P, Dartigues JF. Ginkgo biloba extract and long-term cognitive decline: a 20-year follow-up population-based study. PLoS One. 2013; 8:e52755.

11. Pahaye DB, Bum EN, Taïwé GS, Ngoupaye GT, Sidiki N, Moto FCO, Kouemou N, Njapdounke SJK, Nkantchoua G, Kandeda A. Neuroprotective and antiamnesic effects of Mitragyna inermis willd (Rubiaceae) on scopolamineinduced memory impairment in mice. Behav Neurol. 2017; 2017:5952897.

12. Xu T, Shen X, Yu H, Sun L, Lin W, Zhang C. Watersoluble ginseng oligosaccharides protect against scopolamine-induced cognitive impairment by functioning as an antineuroinflammatory agent. J Ginseng Res. 2016; 40:211-19. 
13. Renjen PN, Gauba C, Chaudhari D. Cognitive impairment after stroke. Cureus. 2015; 7:e335.

14. Ferreira ML. Cognitive deficits in multiple sclerosis: a systematic review. Arq Neuropsiquiatr. 2010; 68:632-41.

15. Aarsland D, Creese B, Politis M, Chaudhuri KR, Ffytche DH, Weintraub D, Ballard C. Cognitive decline in Parkinson disease. Nat Rev Neurol. 2017; 13:217-31.

16. Kim D, Jeon H, Ryu S, Koo S, Ha KT, Kim S. Proteomic analysis of the effect of korean red ginseng in the striatum of a parkinson's disease mouse model. PLoS One. 2016; 11:e0164906.

17. Etemadifar M, Sayahi F, Abtahi SH, Shemshaki H, Dorooshi GA, Goodarzi M, Akbari M, Fereidan-Esfahani $\mathrm{M}$. Ginseng in the treatment of fatigue in multiple sclerosis: a randomized, placebo-controlled, double-blind pilot study. Int J Neurosci. 2013; 123:480-86.

18. Heo JH, Lee ST, Oh MJ, Park HJ, Shim JY, Chu K, Kim M. Improvement of cognitive deficit in Alzheimer's disease patients by long term treatment with korean red ginseng. J Ginseng Res. 2011; 35:457-61.

19. Li Y, Guan Y, Wang Y, Yu CL, Zhai FG, Guan LX. Neuroprotective Effect of the Ginsenoside Rg1 on Cerebral Ischemic Injury In Vivo and In Vitro Is Mediated by PPAR $\gamma$ Regulated Antioxidative and Anti-Inflammatory Pathways. Evidence-Based Complementary and Alternative Medicine. 2017; 2017:7842082. https://doi.org/10.1155/2017/7842082.

20. Deng LL, Yuan D, Zhou ZY, Wan JZ, Zhang CC, Liu CQ, Dun YY, Zhao HX, Zhao B, Yang YJ, Wang T. Saponins from Panax japonicus attenuate age-related neuroinflammation via regulation of the mitogen-activated protein kinase and nuclear factor kappa B signaling pathways. Neural Regen Res. 2017; 12:1877-84.

21. Li N, Liu C, Jing S, Wang M, Wang H, Sun J, Wang C, Chen J, Li H. Compound Schisandra-Ginseng-NotoginsengLycium Extract Ameliorates Scopolamine-Induced Learning and Memory Disorders in Mice. Evid Based Complement Alternat Med. 2017; 2017:8632016. https:// doi.org/10.1155/2017/8632016.

22. Guo X, Lv J, Lu J, Fan L, Huang X, Hu L, Wang J, Shen $\mathrm{X}$. Protopanaxadiol derivative DDPU improves behavior and cognitive deficit in AD mice involving regulation of both ER stress and autophagy. Neuropharmacology. 2018; 130:77-91.

23. Jakaria M, Kim J, Karthivashan G, Park SY, Ganesan P, Choi DK. Emerging signals modulating potential of ginseng and its active compounds focusing on Neurodegenerative diseases. J Ginseng Res. 2018: Ahead of Print. https://doi. org/10.1016/j.jgr.2018.01.001.

24. Sticher O. Getting to the root of ginseng. Chemtech. 1998; 28:26-32.

25. Im DS, Nah SY. Yin and Yang of ginseng pharmacology: ginsenosides vs gintonin. Acta Pharmacol Sin. 2013; 34:1367-73
26. Christensen LP. Ginsenosides chemistry, biosynthesis, analysis, and potential health effects. Adv Food Nutr Res. 2009; 55:1-99.

27. Wang A, Wang CZ, Wu JA, Osinski J, Yuan CS. Determination of major ginsenosides in Panax quinquefolius (American ginseng) using high-performance liquid chromatography. Phytochem Anal. 2005; 16:272-77.

28. Attele AS, Wu JA, Yuan CS. Ginseng pharmacology: multiple constituents and multiple actions. Biochem Pharmacol. 1999; 58:1685-93.

29. Park CS, Yoo MH, Noh KH, Oh DK. Biotransformation of ginsenosides by hydrolyzing the sugar moieties of ginsenosides using microbial glycosidases. Appl Microbiol Biotechnol. 2010; 87:9-19.

30. Kennedy DO, Scholey AB. Ginseng: potential for the enhancement of cognitive performance and mood. Pharmacol Biochem Behav. 2003; 75:687-700.

31. Son JW, Kim HJ, Oh DK. Ginsenoside Rd production from the major ginsenoside $\mathrm{Rb}(1)$ by $\beta$-glucosidase from Thermus caldophilus. Biotechnol Lett. 2008; 30:713-16.

32. Wu CF, Liu YL, Song M, Liu W, Wang JH, Li X, Yang JY. Protective effects of pseudoginsenoside-F11 on methamphetamine-induced neurotoxicity in mice. Pharmacol Biochem Behav. 2003; 76:103-09.

33. Wu G, Yi J, Liu L, Wang $P$, Zhang Z, Li Z. Pseudoginsenoside F11, a novel partial PPAR $\gamma$ agonist, promotes adiponectin oligomerization and secretion in 3T3L1 adipocytes. PPAR Res. 2013; 2013:701017.

34. Meng $\mathrm{X}$, Sun $\mathrm{G}$, Ye J, Xu H, Wang $\mathrm{H}$, Sun $\mathrm{X}$. Notoginsenoside R1-mediated neuroprotection involves estrogen receptor-dependent crosstalk between Akt and ERK1/2 pathways: a novel mechanism of Nrf2/ARE signaling activation. Free Radic Res. 2014; 48:445-60.

35. Wang CZ, Cai Y, Anderson S, Yuan CS. Ginseng metabolites on cancer chemoprevention: an angiogenesis link? Diseases. 2015; 3:193-204.

36. Huang G, Lv J, Li T, Huai G, Li X, Xiang S, Wang L, Qin Z, Pang J, Zou B, Wang Y. Notoginsenoside R1 ameliorates podocyte injury in rats with diabetic nephropathy by activating the PI3K/Akt signaling pathway. Int J Mol Med. 2016; 38:1179-89.

37. Jia C, Xiong M, Wang P, Cui J, Du X, Yang Q, Wang W, Chen Y, Zhang T. Notoginsenoside R1 attenuates atherosclerotic lesions in ApoE deficient mouse model. PLoS One. 2014; 9:e99849.

38. Yosioka I, Sugawara T, Imai K, Kitagawa I. Soil bacterial hydrolysis leading to genuine aglycone. V. on ginsenosides-Rb1, Rb2, and Rc of the ginseng root saponins. Chem Pharm Bull (Tokyo). 1972; 20:2418-21.

39. Karikura M. MIYAsE T, TANIzAwA H, TANIYAMA T, TAKINO Y. Studies on absorption, distribution, excretion and metabolism of ginseng saponins. VII. Comparison of the decomposition modes of ginsenoside- $\mathrm{Rb} 1$ and-Rb2 in 
the digestive tract of rats. Chem Pharm Bull (Tokyo). 1991; 39:2357-61.

40. Hasegawa H, Sung JH, Matsumiya S, Uchiyama M. Main ginseng saponin metabolites formed by intestinal bacteria. Planta Med. 1996; 62:453-57.

41. Qi LW, Wang CZ, Du GJ, Zhang ZY, Calway T, Yuan CS. Metabolism of ginseng and its interactions with drugs. Curr Drug Metab. 2011; 12:818-22.

42. Kim DH. Chemical Diversity of Panax ginseng, Panax quinquifolium, and Panax notoginseng. J Ginseng Res. 2012; 36:1-15.

43. Xie HT, Wang GJ, Chen M, Jiang XL, Li H, Lv H, Huang CR, Wang R, Roberts M. Uptake and metabolism of ginsenoside Rh2 and its aglycon protopanaxadiol by Caco-2 cells. Biol Pharm Bull. 2005; 28:383-86.

44. Han M, Fang XL. Difference in oral absorption of ginsenoside Rg1 between in vitro and in vivo models. Acta Pharmacol Sin. 2006; 27:499-505.

45. Han $M$, Sha X, Wu Y, Fang X. Oral absorption of ginsenoside $\mathrm{Rb} 1$ using in vitro and in vivo models. Planta Med. 2006; 72:398-404.

46. Xu QF, Fang XL, Chen DF. Pharmacokinetics and bioavailability of ginsenoside Rb1 and Rg1 from Panax notoginseng in rats. J Ethnopharmacol. 2003; 84:187-92.

47. Takino Y. Studies on the pharmacodynamics of ginsenoside$\mathrm{Rg} 1,-\mathrm{Rb} 1$ and-Rb2 in rats. Yakugaku zasshi. Journal of the Pharmaceutical Society of Japan. 1994; 114:550-64.

48. Lee BH, Choi SH, Kim HJ, Park SD, Rhim H, Kim HC, Hwang SH, Nah SY. Gintonin absorption in intestinal model systems. J Ginseng Res. 2016.

49. Li L, Sheng YX, Zhang JL, Wang SS, Guo DA. Highperformance liquid chromatographic assay for the active saponins from Panax notoginseng in rat tissues. Biomed Chromatogr. 2006; 20:327-35.

50. Gui FJ, Yang XW, Li LY, Tian JM. Simultaneous enantiomer determination of $20(\mathrm{R})$ - and $20(\mathrm{~S})$-ginsenoside-Rg2 in rat plasma after intravenous administration using HPLC method. J Chromatogr B Analyt Technol Biomed Life Sci. 2007; 850:1-6.

51. Zhang Y, Lin L, Liu GY, Liu JX, Li T. [Pharmacokinetics and brain distribution of ginsenosides after administration of sailuotong]. Zhongguo Zhong Yao Za Zhi. 2014; 39:316-21.

52. Akao T, Kida H, Kanaoka M, Hattori M, Kobashi K. Intestinal bacterial hydrolysis is required for the appearance of compound $\mathrm{K}$ in rat plasma after oral administration of ginsenoside Rb1 from Panax ginseng. J Pharm Pharmacol. 1998; 50:1155-60.

53. Paek IB, Moon Y, Kim J, Ji HY, Kim SA, Sohn DH, Kim JB, Lee HS. Pharmacokinetics of a ginseng saponin metabolite compound $\mathrm{K}$ in rats. Biopharm Drug Dispos. 2006; 27:39-45.

54. Lee PS, Song TW, Sung JH, Moon DC, Song S, Chung YB. Pharmacokinetic characteristics and hepatic distribution of
IH-901, a novel intestinal metabolite of ginseng saponin, in rats. Planta Med. 2006; 72:204-10.

55. Liu H, Yang J, Du F, Gao X, Ma X, Huang Y, Xu F, Niu W, Wang F, Mao Y. Absorption and disposition of ginsenosides after oral administration of Panax notoginseng extract to rats. Drug Metab Dispos. 2009; 37:2290-8. https://doi. org/10.1124/dmd.109.029819.

56. Chi H, Kim DH, Ji GE. Transformation of ginsenosides Rb2 and Rc from Panax ginseng by food microorganisms. Biol Pharm Bull. 2005; 28:2102-05.

57. Chi H, Ji GE. Transformation of ginsenosides Rb1 and Re from Panax ginseng by food microorganisms. Biotechnol Lett. 2005; 27:765-71.

58. Hasegawa H, Uchiyama M. Antimetastatic efficacy of orally administered ginsenoside Rb1 in dependence on intestinal bacterial hydrolyzing potential and significance of treatment with an active bacterial metabolite. Planta Med. 1998; 64:696-700.

59. Xiong J, Guo J, Huang L, Meng B, Ping Q. The use of lipidbased formulations to increase the oral bioavailability of Panax notoginseng saponins following a single oral gavage to rats. Drug Dev Ind Pharm. 2008; 34:65-72.

60. Han M, Fu S, Gao JQ, Fang XL. Evaluation of intestinal absorption of ginsenoside $\mathrm{Rg} 1$ incorporated in microemulison using parallel artificial membrane permeability assay. Biol Pharm Bull. 2009; 32:1069-74.

61. Cui JF, Björkhem I, Eneroth P. Gas chromatographic-mass spectrometric determination of 20(S)-protopanaxadiol and 20(S)-protopanaxatriol for study on human urinary excretion of ginsenosides after ingestion of ginseng preparations. J Chromatogr B Biomed Sci Appl. 1997; 689:349-55.

62. Chen SE, Sawchuk RJ, Staba EJ. American ginseng. III. Pharmacokinetics of ginsenosides in the rabbit. Eur J Drug Metab Pharmacokinet. 1980; 5:161-68.

63. Tawab MA, Bahr U, Karas M, Wurglics M, SchubertZsilavecz M. Degradation of ginsenosides in humans after oral administration. Drug Metab Dispos. 2003; 31:1065-71.

64. Hasegawa H. Proof of the mysterious efficacy of ginseng: basic and clinical trials: metabolic activation of ginsenoside: deglycosylation by intestinal bacteria and esterification with fatty acid. J Pharmacol Sci. 2004; 95:153-57.

65. Chen $\mathrm{C}$, Zhang $\mathrm{H}, \mathrm{Xu} \mathrm{H}$, Zheng $\mathrm{Y}, \mathrm{Wu} \mathrm{T}$, Lian Y. Ginsenoside Rb1 ameliorates cisplatin-induced learning and memory impairments. J Ginseng Res. 2017. https://doi. org/10.1016/j.jgr.2017.07.009.

66. Miao HH, Zhang Y, Ding GN, Hong FX, Dong P, Tian M. Ginsenoside Rb1 Attenuates Isoflurane/surgery-induced Cognitive Dysfunction via Inhibiting Neuroinflammation and Oxidative Stress. Biomed Environ Sci. 2017; 30:363-72.

67. Li Y, Tang J, Khatibi NH, Zhu M, Chen D, Tu L, Chen L, Wang S. Treatment with ginsenoside rb1, a component of panax ginseng, provides neuroprotection in rats subjected to 
subarachnoid hemorrhage-induced brain injury. Early Brain Injury or Cerebral Vasospasm. Springer; 2011. pp. 75-9.

68. Wu Y, Huang XF, Bell C, Yu Y. Ginsenoside Rb1 improves leptin sensitivity in the prefrontal cortex in obese mice. CNS Neurosci Ther. 2018; 24:98-107.

69. Liu L, Hoang-Gia T, Wu H, Lee MR, Gu L, Wang C, Yun BS, Wang Q, Ye S, Sung CK. Ginsenoside Rb1 improves spatial learning and memory by regulation of cell genesis in the hippocampal subregions of rats. Brain Res. 2011; 1382:147-54.

70. Wang Q, Sun LH, Jia W, Liu XM, Dang HX, Mai WL, Wang N, Steinmetz A, Wang YQ, Xu CJ. Comparison of ginsenosides $\mathrm{Rg} 1$ and $\mathrm{Rb} 1$ for their effects on improving scopolamine-induced learning and memory impairment in mice. Phytother Res. 2010; 24:1748-54.

71. Ye J, Yao JP, Wang X, Zheng M, Li P, He C, Wan JB, Yao $\mathrm{X}, \mathrm{Su} \mathrm{H}$. Neuroprotective effects of ginsenosides on neural progenitor cells against oxidative injury. Mol Med Rep. 2016; 13:3083-91.

72. Ni N, Liu Q, Ren H, Wu D, Luo C, Li P, Wan JB, Su H. Ginsenoside $\mathrm{Rb} 1$ protects rat neural progenitor cells against oxidative injury. Molecules. 2014; 19:3012-24.

73. Zhang YL, Liu Y, Kang XP, Dou CY, Zhuo RG, Huang SQ, Peng L, Wen L. Ginsenoside Rb1 confers neuroprotection via promotion of glutamate transporters in a mouse model of Parkinson's disease. Neuropharmacology. 2018; 131:223-37.

74. Liu J, Yan X, Li L, Li Y, Zhou L, Zhang X, Hu X, Zhao G. Ginsenoside Rd improves learning and memory ability in APP transgenic mice. J Mol Neurosci. 2015; 57:522-28.

75. Yan X, Hu G, Yan W, Chen T, Yang F, Zhang X, Zhao G, Liu J. Ginsenoside Rd promotes non-amyloidogenic pathway of amyloid precursor protein processing by regulating phosphorylation of estrogen receptor alpha. Life Sci. 2017; 168:16-23.

76. Hou J, Xue J, Lee M, Sung C. Ginsenoside Rd as a potential neuroprotective agent prevents trimethyltin injury. Biomed Rep. 2017; 6:435-40.

77. Wu SD, Xia F, Lin XM, Duan KL, Wang F, Lu QL, Cao H, Qian YH, Shi M. Ginsenoside-Rd promotes neurite outgrowth of PC12 cells through MAPK/ERK-and PI3K/ AKT-dependent pathways. Int J Mol Sci. 2016; 17:177.

78. Lee KW, Jung SY, Choi SM, Yang EJ. Effects of ginsenoside Re on LPS-induced inflammatory mediators in BV2 microglial cells. BMC Complement Altern Med. 2012; 12:196.

79. Zhao Y, Liu J, Lu D, Zhao Y, Li P. Improvement effect of ginsenoside Re on learning and memory abilities of natural apolexis eats and its mechanisms. Tradit Chin Drug Res Clin Pharm. 2007; 18:20-22.

80. Lee B, Shim I, Lee H, Hahm DH. Effect of ginsenoside Re on depression- and anxiety-like behaviors and cognition memory deficit induced by repeated immobilization in rats. J Microbiol Biotechnol. 2012; 22:708-20.

81. Liu YW, Zhu X, Li W, Lu Q, Wang JY, Wei YQ, Yin XX. Ginsenoside Re attenuates diabetes-associated cognitive deficits in rats. Pharmacol Biochem Behav. 2012; 101:93-98.

82. Kim JM, Park CH, Park SK, Seung TW, Kang JY, Ha JS, Lee DS, Lee U, Kim DO, Heo HJ. Ginsenoside Re ameliorates brain insulin resistance and cognitive dysfunction in high fat diet-induced C57BL/6 mice. J Agric Food Chem. 2017; 65:2719-29.

83. Xia C, Kewei M, Yicheng L, Xiaofeng Y, Yanping C, Dayuan S, Jin P, Xinquan G. (2011). Effects of Ginsenoside $\mathrm{Re}$ on myocardial ischemia reperfusion injury. Human Health and Biomedical Engineering (HHBE), 2011 International Conference on: IEEE), pp. 96-9. https://doi. org/10.1109/HHBE.2011.6027905.

84. Shi J, Xue W, Zhao WJ, Li KX. Pharmacokinetics and dopamine/acetylcholine releasing effects of ginsenoside Re in hippocampus and mPFC of freely moving rats. Acta Pharmacol Sin. 2013; 34:214-20.

85. Tran TV, Shin EJ, Dang DK, Ko SK, Jeong JH, Nah SY, Jang CG, Lee YJ, Toriumi K, Nabeshima T, Kim HC. Ginsenoside Re protects against phencyclidine-induced behavioral changes and mitochondrial dysfunction via interactive modulation of glutathione peroxidase- 1 and NADPH oxidase in the dorsolateral cortex of mice. Food Chem Toxicol. 2017; 110:300-15.

86. Qi D, Zhu Y, Wen L, Liu Q, Qiao H. Ginsenoside Rg1 restores the impairment of learning induced by chronic morphine administration in rats. J Psychopharmacol. 2009; 23:74-83.

87. Zhu J, Mu X, Zeng J, Xu C, Liu J, Zhang M, Li C, Chen J, Li T, Wang Y. Ginsenoside Rg1 prevents cognitive impairment and hippocampus senescence in a rat model of D-galactose-induced aging. PLoS One. 2014; 9:e101291.

88. Yang L, Zhang J, Zheng K, Shen H, Chen X. Longterm ginsenoside $\mathrm{Rg} 1$ supplementation improves agerelated cognitive decline by promoting synaptic plasticity associated protein expression in C57BL/6J mice. J Gerontol A Biol Sci Med Sci. 2014; 69:282-94.

89. Kezhu W, Pan X, Cong L, Liming D, Beiyue Z, Jingwei L, Yanyan Y, Xinmin L. Effects of Ginsenoside Rg1 on Learning and Memory in a Reward-directed Instrumental Conditioning Task in Chronic Restraint Stressed Rats. Phytother Res. 2017; 31:81-89.

90. Zhang Y, Zhang Z, Wang H, Cai N, Zhou S, Zhao Y, Chen X, Zheng S, Si Q, Zhang W. Neuroprotective effect of ginsenoside $\mathrm{Rg} 1$ prevents cognitive impairment induced by isoflurane anesthesia in aged rats via antioxidant, anti-inflammatory and anti-apoptotic effects mediated by the PI3K/AKT/GSK-3 $\beta$ pathway. Mol Med Rep. 2016; 14:2778-84. 
91. Jin Y, Peng J, Wang X, Zhang D, Wang T. Ameliorative effect of ginsenoside $\mathrm{Rg} 1$ on lipopolysaccharide-induced cognitive impairment: role of cholinergic system. Neurochem Res. 2017; 42:1299-307.

92. Zhang Y, Hu W, Zhang B, Yin Y, Zhang J, Huang D, Huang R, Li W, Li W. Ginsenoside Rg1 protects against neuronal degeneration induced by chronic dexamethasone treatment by inhibiting NLRP-1 inflammasomes in mice. Int $\mathrm{J}$ Mol Med. 2017; 40:1134-42.

93. Li Y, Wang F, Luo Y. Ginsenoside Rg1 protects against sepsis-associated encephalopathy through beclin 1-independent autophagy in mice. J Surg Res. 2017; 207:181-89.

94. Zhu G, Wang Y, Li J, Wang J. Chronic treatment with ginsenoside $\mathrm{Rg} 1$ promotes memory and hippocampal longterm potentiation in middle-aged mice. Neuroscience. 2015; 292:81-89.

95. Ghaeminia M, Rajkumar R, Koh HL, Dawe GS, Tan CH. Ginsenoside Rg1 modulates medial prefrontal cortical firing and suppresses the hippocampo-medial prefrontal cortical long-term potentiation. J Ginseng Res. 2017.

96. Li F, Wu X, Li J, Niu Q. Ginsenoside Rg1 ameliorates hippocampal long-term potentiation and memory in an Alzheimer's disease model. Mol Med Rep. 2016; 13:4904-10.

97. Nie L, Xia J, Li H, Zhang Z, Yang Y, Huang X, He Z, Liu J, Yang X. Ginsenoside Rg1 Ameliorates Behavioral Abnormalities and Modulates the Hippocampal Proteomic Change in Triple Transgenic Mice of Alzheimer's Disease. Oxid Med Cell Longev. 2017;2017:6473506. https://doi. org/10.1155/2017/6473506.

98. Zhang G, Liu A, Zhou Y, San X, Jin T, Jin Y. Panax ginseng ginsenoside-Rg2 protects memory impairment via anti-apoptosis in a rat model with vascular dementia. J Ethnopharmacol. 2008; 115:441-48.

99. Lee B, Sur B, Park J, Kim SH, Kwon S, Yeom M, Shim I, Lee H, Hahm DH. Ginsenoside rg3 alleviates lipopolysaccharide-induced learning and memory impairments by anti-inflammatory activity in rats. Biomol Ther (Seoul). 2013; 21:381-90.

100. Kim J, Shim J, Lee S, Cho WH, Hong E, Lee JH, Han JS, Lee HJ, Lee KW. Rg3-enriched ginseng extract ameliorates scopolamine-induced learning deficits in mice. BMC Complement Altern Med. 2016; 16:66.

101. Peña ID, Yoon SY, Kim HJ, Park S, Hong EY, Ryu JH, Park $\mathrm{IH}$, Cheong JH. Effects of ginseol k-g3, an Rg3-enriched fraction, on scopolamine-induced memory impairment and learning deficit in mice. J Ginseng Res. 2014; 38:1-7.

102. Hou J, Kim S, Sung C, Choi C. Ginsenoside Rg3 Prevents Oxidative Stress-Induced Astrocytic Senescence and Ameliorates Senescence Paracrine Effects on Glioblastoma. Molecules. 2017; 22:1516.

103. Zhang H, Zhou Z, Chen Z, Zhong Z, Li Z. Ginsenoside Rg3 exerts anti-depressive effect on an NMDA-treated cell model and a chronic mild stress animal model. J Pharmacol Sci. 2017; 134:45-54.

104. Aalinkeel R, Kutscher HL, Singh A, Cwiklinski K, Khechen N, Schwartz SA, Prasad PN, Mahajan SD. Neuroprotective effects of a biodegradable poly(lactic-co-glycolic acid)ginsenoside $\mathrm{Rg} 3$ nanoformulation: a potential nanotherapy for Alzheimer's disease? J Drug Target. 2018; 26:182-93.

105. Wang YZ, Chen J, Chu SF, Wang YS, Wang XY, Chen NH, Zhang JT. Improvement of memory in mice and increase of hippocampal excitability in rats by ginsenoside Rg1's metabolites ginsenoside Rh1 and protopanaxatriol. J Pharmacol Sci. 2009; 109:504-10.

106. Kim EJ, Jung IH, Van Le TK, Jeong JJ, Kim NJ, Kim DH. Ginsenosides Rg5 and Rh3 protect scopolamineinduced memory deficits in mice. J Ethnopharmacol. 2013; 146:294-99.

107. Hou J, Xue J, Lee M, Yu J, Sung C. Long-term administration of ginsenoside Rh1 enhances learning and memory by promoting cell survival in the mouse hippocampus. Int J Mol Med. 2014; 33:234-40.

108. Lu C, Shi Z, Dong L, Lv J, Xu P, Li Y, Qu L, Liu X. Exploring the Effect of Ginsenoside Rh1 in a Sleep Deprivation-Induced Mouse Memory Impairment Model. Phytother Res. 2017; 31:763-70.

109. Hou J, Xue J, Lee M, Liu L, Zhang D, Sun M, Zheng Y, Sung C. Ginsenoside Rh2 improves learning and memory in mice. J Med Food. 2013; 16:772-76.

110. Li Z, Guo YY, Wu CF, Li X, Wang JH. Protective effects of pseudoginsenoside-F11 on scopolamine-induced memory impairment in mice and rats. J Pharm Pharmacol. 1999; 51:435-40.

111. Li Z, Wu CF, Pei G, Guo YY, Li X. Antagonistic effect of pseudoginsenoside-F11 on the behavioral actions of morphine in mice. Pharmacol Biochem Behav. 2000; 66:595-601.

112. Fu K, Lin H, Miyamoto Y, Wu C, Yang J, Uno K, Nitta A. Pseudoginsenoside-F11 inhibits methamphetamine-induced behaviors by regulating dopaminergic and GABAergic neurons in the nucleus accumbens. Psychopharmacology (Berl). 2016; 233:831-40.

113. Wang CM, Liu MY, Wang F, Wei MJ, Wang S, Wu CF, Yang JY. Anti-amnesic effect of pseudoginsenoside-F11 in two mouse models of Alzheimer's disease. Pharmacol Biochem Behav. 2013; 106:57-67.

114. Wang JY, Yang JY, Wang F, Fu SY, Hou Y, Jiang B, Ma J, Song C, Wu CF. Neuroprotective effect of pseudoginsenoside-f11 on a rat model of Parkinson's disease induced by 6-hydroxydopamine. EvidenceBased Complementary and Alternative Medicine. 2013; 2013:152798.

115. Liu YY, Zhang TY, Xue X, Liu DM, Zhang HT, Yuan LL, Liu YL, Yang HL, Sun SB, Zhang C, Xu HS, Wu CF, Yang JY. Pseudoginsenoside-F11 attenuates cerebral ischemic injury by alleviating autophagic/lysosomal defects. CNS Neurosci Ther. 2017; 23:567-79. 
116. Gu B, Nakamichi N, Zhang WS, Nakamura Y, Kambe Y, Fukumori R, Takuma K, Yamada K, Takarada T, Taniura H, Yoneda Y. Possible protection by notoginsenoside R1 against glutamate neurotoxicity mediated by N-methyl-Daspartate receptors composed of an NR1/NR2B subunit assembly. J Neurosci Res. 2009; 87:2145-56.

117. Ma B, Meng X, Wang J, Sun J, Ren X, Qin M, Sun J, Sun G, Sun $X$. Notoginsenoside R1 attenuates amyloid- $\beta$-induced damage in neurons by inhibiting reactive oxygen species and modulating MAPK activation. Int Immunopharmacol. 2014; 22:151-59.

118. Yan S, Li Z, Li H, Arancio O, Zhang W. Notoginsenoside $\mathrm{R} 1$ increases neuronal excitability and ameliorates synaptic and memory dysfunction following amyloid elevation. Sci Rep. 2014; 4:6352.

119. Li Z, Li H, Zhao C, Lv C, Zhong C, Xin W, Zhang W. Protective Effect of Notoginsenoside R1 on an APP/ PS1 Mouse Model of Alzheimer and Aposs Disease by Up-Regulating Insulin Degrading Enzyme and Inhibiting A $\beta$ Accumulation. CNS \& Neurological DisordersDrug Targets (Formerly Current Drug Targets-CNS \& Neurological Disorders). 2015; 14: 360-9.

120. Zhai Y, Meng X, Luo Y, Wu Y, Ye T, Zhou P, Ding S, Wang M, Lu S, Zhu L, Sun G, Sun X. Notoginsenoside R1 ameliorates diabetic encephalopathy by activating the Nrf2 pathway and inhibiting NLRP3 inflammasome activation. Oncotarget. 2018; 9:9344-63. https://doi.org/10.18632/ oncotarget.24295.

121. Kim S, Kim MS, Park K, Kim HJ, Jung SW, Nah SY, Han JS, Chung C. Hippocampus-dependent cognitive enhancement induced by systemic gintonin administration. J Ginseng Res. 2016; 40:55-61.

122. Hwang SH, Shin EJ, Shin TJ, Lee BH, Choi SH, Kang J, Kim HJ, Kwon SH, Jang CG, Lee JH, Kim HC, Nah SY. Gintonin, a ginseng-derived lysophosphatidic acid receptor ligand, attenuates Alzheimer's disease-related neuropathies: involvement of non-amyloidogenic processing. J Alzheimers Dis. 2012; 31:207-23.

123. Kim HJ, Shin EJ, Lee BH, Choi SH, Jung SW, Cho IH, Hwang SH, Kim JY, Han JS, Chung C, Jang CG, Rhim H, Kim HC, Nah SY. Oral administration of gintonin attenuates cholinergic impairments by scopolamine, amyloid- $\beta$ protein, and mouse model of Alzheimer's disease. Mol Cells. 2015; 38:796-805.

124. Park H, Kim S, Rhee J, Kim HJ, Han JS, Nah SY, Chung C. Synaptic enhancement induced by gintonin via lysophosphatidic acid receptor activation in central synapses. J Neurophysiol. 2015; 113:1493-500.

125. Shin TJ, Kim HJ, Kwon BJ, Choi SH, Kim HB, Hwang $\mathrm{SH}$, Lee BH, Lee SM, Zukin RS, Park JH, Kim HC, Rhim H, Lee JH, Nah SY. Gintonin, a ginseng-derived novel ingredient, evokes long-term potentiation through $\mathrm{N}$-methyl-D-aspartic acid receptor activation: involvement of LPA receptors. Mol Cells. 2012; 34:563-72.
126. Kim HJ, Kim DJ, Shin EJ, Lee BH, Choi SH, Hwang SH, Rhim H, Cho IH, Kim HC, Nah SY. Effects of gintoninenriched fraction on hippocampal cell proliferation in wildtype mice and an APPswe/PSEN-1 double Tg mouse model of Alzheimer's disease. Neurochem Int. 2016; 101:56-65.

127. Hou JG, Xue JJ, Lee MR, Sun MQ, Zhao XH, Zheng YN, Sung CK. Compound $\mathrm{K}$ is able to ameliorate the impaired cognitive function and hippocampal neurogenesis following chemotherapy treatment. Biochem Biophys Res Commun. 2013; 436:104-09.

128. Seo JY, Ju SH, Oh J, Lee SK, Kim JS. Neuroprotective and cognition-enhancing effects of compound $\mathrm{K}$ isolated from red ginseng. J Agric Food Chem. 2016; 64:2855-64.

129. Park JS, Shin JA, Jung JS, Hyun JW, Van Le TK, Kim DH, Park EM, Kim HS. Anti-inflammatory mechanism of compound $\mathrm{K}$ in activated microglia and its neuroprotective effect on experimental stroke in mice. J Pharmacol Exp Ther. 2012; 341:59-67.

130. Guo J, Chang L, Zhang X, Pei S, Yu M, Gao J. Ginsenoside compound $\mathrm{K}$ promotes $\beta$-amyloid peptide clearance in primary astrocytes via autophagy enhancement. Exp Ther Med. 2014; 8:1271-74.

131. Lee ST, Chu K, Sim JY, Heo JH, Kim M. Panax ginseng enhances cognitive performance in Alzheimer disease. Alzheimer Dis Assoc Disord. 2008; 22:222-26.

132. Yeo HB, Yoon HK, Lee HJ, Kang SG, Jung KY, Kim L. Effects of Korean red ginseng on cognitive and motor function: a double-blind, randomized, placebo-controlled trial. J Ginseng Res. 2012; 36:190-97.

133. Park K, Jin H, Rhee HY, Kim S, Lee SE, Kim YO, Kim GS, Kim SY, Yim SV, Choi YC. A randomized, double-blind, placebo-controlled clinical trial of Korean ginseng as a functional food in mild cognitive impairment. Alzheimers Dement. 2013; 9:804.

134. Scholey A, Ossoukhova A, Owen L, Ibarra A, Pipingas A, He K, Roller M, Stough C. Effects of American ginseng (Panax quinquefolius) on neurocognitive function: an acute, randomised, double-blind, placebo-controlled, crossover study. Psychopharmacology (Berl). 2010; 212:345-56.

135. Sutherland SK, Purdon SE, Lai C, Wang LJ, Liu GZ, Shan JJ. Memory enhancement from two weeks' exposure to North American ginseng extract HT1001 in young and middle aged healthy adults. Open Nutraceuticals J. 2010; 3:20-24.

136. Kim H, Lee JH, Kim JE, Kim YS, Ryu CH, Lee HJ, Kim HM, Jeon H, Won HJ, Lee JY, Lee J. Micro-/nano-sized delivery systems of ginsenosides for improved systemic bioavailability. J Ginseng Res. 2018; 42:361-69.

137. Zhang S, Liu J, Ge B, Du M, Fu L, Fu Y, Yan Q. Enhanced antitumor activity in A431 cells via encapsulation of 20(R)-ginsenoside Rg3 in PLGA nanoparticles. Drug Dev Ind Pharm. 2017; 43:1734-41.

138. Singh P, Kim YJ, Singh H, Ahn S, Castro-Aceituno V, Yang DC. In situ preparation of water-soluble ginsenoside 
Rh2-entrapped bovine serum albumin nanoparticles: in vitro cytocompatibility studies. Int J Nanomedicine. 2017; 12:4073-84.

139. Yang L, Xin J, Zhang Z, Yan H, Wang J, Sun E, Hou J, Jia X, Lv H. TPGS-modified liposomes for the delivery of ginsenoside compound $\mathrm{K}$ against non-small cell lung cancer: formulation design and its evaluation in vitro and in vivo. J Pharm Pharmacol. 2016; 68:1109-18.

140. Xu L, Yu H, Yin S, Zhang R, Zhou Y, Li J. Liposome-based delivery systems for ginsenoside $\mathrm{Rh} 2$ : in vitro and in vivo comparisons. J Nanopart Res. 2015; 17:415.

141. Yu H, Teng L, Meng Q, Li Y, Sun X, Lu J, J Lee R, Teng L. Development of liposomal Ginsenoside Rg3: formulation optimization and evaluation of its anticancer effects. Int $\mathrm{J}$ Pharm. 2013; 450:250-58.
142. Li T, Shu YJ, Cheng JY, Liang RC, Dian SN, Lv XX, Yang MQ, Huang SL, Chen G, Yang F. Pharmacokinetics and efficiency of brain targeting of ginsenosides Rg1 and Rb1 given as Nao-Qing microemulsion. Drug Dev Ind Pharm. 2015; 41:224-31.

143. Lu T, Jiang Y, Zhou Z, Yue X, Wei N, Chen Z, Ma M, Xu $\mathrm{G}$, Liu X. Intranasal ginsenoside Rb1 targets the brain and ameliorates cerebral ischemia/reperfusion injury in rats. Biol Pharm Bull. 2011; 34:1319-24.

144. Shen J, Zhao Z, Shang W, Liu C, Zhang B, Zhao L, Cai H. Ginsenoside Rg1 nanoparticle penetrating the blood-brain barrier to improve the cerebral function of diabetic rats complicated with cerebral infarction. Int J Nanomedicine. 2017; 12:6477-86. 